\title{
Notas sobre El Manuscrito de Palacio II-1520, adiciones marginales y controversias filológicas
}

\author{
Fernando Cantalapiedra Erostarbe \\ UNED-Jaén
}

A Marcelino Amasuno

A finales de los años setenta sugerí1 que lo que Fernando de Rojas encontró no fue el primer acto de La Celestina, como se da a entender en los paratextos de la Tragicomedia $(=C L-21)$ y aceptaba entonces mayoritariamente la crítica, sino una comedia terenciana que abarcaba, en la distribución impresa, los doce primeros actos $(=C L-12)$; y que sobre esta base textual añadió, eliminó, modificó, diseminó y acabó su tragedia humanística: los cuatro últimos actos de la versión en $16(=C L-16) ;^{2}$ este segundo autor añadió además la escena inicial de la obra ${ }^{3}$ la primera aparición escénica de Pleberio, ${ }^{4}$ inventó los nuevos personajes - Sosia, Tristán y Pleberio-y modificó los otros, ${ }^{5}$ creó nuevos espacios ${ }^{6}$ - huerto y torre-; modificó asimismo el texto de CL-12, incluido el primer acto, con supresiones, sustituciones y añadidos ${ }^{7}$ para ajustarlo a la tragedia, ${ }^{8}$ tal y como se hizo con los añadidos impresos, anteriores a 1505, que aparecen en la versión de 21 actos, en la cual se incorporó a la obra los cinco actos

1.- Fernando Cantalapiedra, Pour une analyse sémiotique de La Célestine de F. de Rojas. Thèse de III cycle. Université de Paris III, Sorbonne, Paris, janvier 1979.

2.- Cantalapiedra (1979: 36-39, 66, 351, 386-389, 431, 434...). «La fin de 16 actes sur les 12 trouvés n'est que de quatre actes», pp. 429-430.

3.- Cantalapiedra (1979: 72, 279, 296, 299, 352, 432...). También «La escena de la huertahuerto", en Criado de Val (dir.), Literatura Hispánica. Reyes Católicos y Descubrimiento, Barcelona PPU, 1989, pp. 317-327.

4.- Cantalapiedra (1979: 36-39, 129, 137, 423).

5.- Cantalapiedra (1979: 297, 423, 435).

6.- Cantalapiedra (1979: 34, 52-53, 435).

7.- «qui peut affimer que la première édition [de CL-16] n'a pas modifié le [...] manuscrit, et qu'elle n'a pas, par conséquent, ajouté du texte au premier acte?». Cantalapiedra (1979: 42, 46 y 299).

8.- Cantalapiedra (1979: 39, 66, 158, 295). 
nuevos del llamado Tratado de Centurio, obra del segundo autor. ${ }^{9}$ Dichos añadidos impresos son tan numerosos que afectan a la propia teatralidad de la obra, al casi duplicar el número de líneas pronunciadas por los personajes, lo que implica que el autor de CL-12, la comedia terenciana, tenía una clara y evidente visión teatral y un equilibrio dramático entre los personajes, mientras que Fernando de Rojas (CL-16 y CL-21) ofrece una visión más narrativa. ${ }^{10}$ Planteaba asimismo como dudosas las muertes por defenestración desde los pequeños ventanucos de una primera planta de Pármeno y Sempronio y me preguntaba si Rojas había terminado, modificado, escrito o mal interpretado el pasaje. ${ }^{11}$ En realidad la primitiva comedia planteaba un final terenciano, abierto, ¿había muerto Celestina? ¿Se pusieron a salvo los criados? Cabe recordar que Feliciano de Silva interpretó que la vieja Trotaconventos había sobrevivido a las heridas infringidas por Pármeno y Sempronio: "yo vine aquí, a casa del Arcediano viejo, [...] a ser encubierta de la vengança que de los criados de Calisto yo quise tomar, fingiendo con mis artes que era muerta». ${ }^{12}$ Recurso que ya había empleado anteriormente Garci Rodríguez de Montalvo, quien reorganizó y reelaboró los tres primeros libros ya existentes en forma manuscrita del Amadís de Gaula - modificando la dispositio y la trama narrativa y eliminando la muerte de Amadís y Oriana-, añadió un cuarto libro; y, tras su éxito editorial, escribió el quinto libro titulado Las sergas de Esplandián. ${ }^{13}$ Esta aventura editorial tuvo lugar en los mismos años entre 1495 y 1497- en los que CL pasó de manuscrito, o mejor dicho manuscritos, a obra impresa de 16 actos y luego a pieza de 21 actos; y en

9.- Cantalapiedra (1979: 195, 297, 354, 423, 435).

10.- Cantalapiedra (1979: 124, 185). Véase también Fernando Cantalapiedra Erostarbe, «Sentencias petrarquistas y adiciones a la TragiComedia de Calisto y Melibea», en P. Botta, F. Cantalapiedra, K. Reichenberger y J. T. Snow (eds.), Tras los pasos de 'La Celestina', Kassel, Edition Reichenberger, 2001, pp. 55-59.

11.- Cantalapiedra (1979: 296-297). Indiqué en mi edición crítica que la escena de la huida pertenece al primer autor. Cfr. Anónimo / Fernando de Rojas, TragiComedia de Calisto y Melibea, edición crítica de Fernando Cantalapiedra Erostarbe, Kassel, Edition Reichenberger 2000, 3 vols. La cita en t. II, p. 661. Estas cuestiones las he tratado en varios estudios, y entre otros: Lectura semiótico-formal de "La Celestina", Kassel, Reichenberger, 1986; "Apuntes didácticos sobre la estructura de La Celestina y el problema de su autoría", en Actas das I. Xornadas de Didáctica da literatura, Universidad de Santiago de Compostela, 1987, pp. 41-54. También en el primer tomo de la TragiComedia dedicado al asunto de la autoría y en las notas de los tomos II y III.

12.- Feliciano de Silva, Segunda Celestina, edición de Consolación Baranda, Madrid, Cátedra, 1988, pp. 167-168.

13.- Garci Rodríguez de Montalvo, Amadís de Gaula, edición de Juan Manuel Cacho Blecua, Madrid, Cátedra, 1988. En las Sergas se precisa la resurrección: "que Amadís no murió de estas heridas, y de cómo declaró al rey la causa [...] / algunos dixeron que en ella [esta cruel y dura batalla] Amadís de aquellas heridas muriera [... y sabido por Oriana se despeñó de una ventana abaxo. Mas no fue así, que el gran maestro Helisabad le sanó de sus llagas [...] y fueron reyes él [Amadís] y Oriana». Garci Rodríguez de Montalvo, Las sergas de Esplandián, Alcalá de Henares, Herederos de Juan Gracián, 1588. BNM, signatura R/ 13138 (1). Cap. xxIx, f. 33v. 
ambos casos, el de Amadís y el de Celestina, se detecta la presencia y las octavas, similares en contenido, forma y léxico, del corrector Alonso de Proaza, ${ }^{14}$ y quizá los mismos lugares de impresión.

Jospeh T. Snow señalaba años después en el prólogo a uno de mis libros y estableciendo un paralelismo con los trabajos de Miguel Marciales que "donde una puerta se cierra, otra se abre». ${ }^{15}$ Sobre el primer encuentro de Calisto y Melibea en la huerta, Martín de Riquer ya había apuntado, retomando una idea de Anna Krause, ${ }^{16}$ que «Fernando de Rojas mudó completamente el decorado de esta primera escena» (el de una iglesia por una huerta, según el argumento), y "hace sospechar que la primitiva redacción de La Celestina empezaba antes y que esta escena iba precedida de otras». No obstante, pensaba que todos esos cambios los hizo Rojas sin tocar el primer acto y desde el «respeto que siente por la labor del autor primitivo del principio de la obra, en cuyo texto no quiere verificar modificaciones personales». ${ }^{17}$ Por otro lado, Miguel Marciales escribía sobre esa inicial escena "que es tan dispar en estilo con lo que sigue del Auto I, que pudiera hasta pensarse que fue escrita por otro, que no Cota, algún amigo o conocido. ¿Proaza? ¿Diego de san Pedro? ¿Juan de Lucena? ${ }^{18}$ [...] el haber sido pergeñada ex post scripto, esto es después de escrito el resto del esbozo [...]», y ya en su edición crítica en el primer diálogo de Calisto con Sempronio indica "se trata de una nueva escena en casa de Calisto, muchos día después del encuentro con Melibea en la cena $1^{a} »{ }^{a}{ }^{19}$ Por esas mismas fechas Miguel Garci-Gómez ${ }^{20}$ argumentaba que se trata de una escena soñada; un lustro después, Ricardo Castells ${ }^{21}$ desarrollaba esa idea de la escena inicial como un sueño de Calisto.

Según Marciales, Rojas "no toca ni enmienda el manuscrito de Cota», que abarca hasta la segunda escena del acto segundo: «los mismos aris-

14.- Jordi Pardo Pastor, "Alonso de Proaza, homo litterarum, corrector et excelsus editor», en Covenit Selecta, 3 (2000): <http://www.hottopos.com/convenit3/jordipar.htm\#_ftnref10>. La primera edición conocida de Las Sergas de Esplandián está fechada en 1510 en Sevilla, pero hubo al menos otra edición anterior en la misma ciudad.

15.- Lectura semiótico-formal de La Celestina, (1986: 13).

16.- Anna Krause, "Deciphering the epistle-preface to the Comedia de Calisto y Melibea", Romanic Review, XLIV (1953), pp. 89-101.

17.- Martín de Riquer, "Fernando de Rojas y el primer acto de 'La Celestina'», Revista de Filología Española, XLI-1/4 (1957), pp. 371-395. Las citas en las pp. 389, 388, 392.

18.- Lo que implica la presencia de cuatro autores: uno de los aquí citados, más Cota, Rojas y Sanabria.

19.- Miguel Marciales (ed.), Fernando de Rojas, Celestina. Tragicomedia de Calisto y Melibea. Al cuidado de Brian Dutton y Joseph T. Snow, Urbana and Chicago, University of Illinois Press, 1985, 2 vols. Citas: I, p. 275 y II, p. 19.

20.- Miguel Garci-Gómez, «El sueño de Calisto», Celestinesca, 9-1 (1985), pp.11-22.

21.- Ricardo Castells, «El sueño de Celestina y la tradición celestinesca», Celestinesca, 14-1 (1990), pp.17-39. 
toteleos y escolastiquerías del actual acto $I^{2} ; 2$ tampoco observa adiciones primeras ya en el texto de CL-16 hasta el acto tercero, III.7-9. Que la creación del antiguo autor iba más allá del primer acto ya lo sospechó Castro Guisasola ${ }^{23}$ y lo recordó Martín de Riquer. ${ }^{24}$ Ese efecto referencial de "aristoteleos y escolastiquerías» proviene no del empleo de varias fuentes filosóficas como se había creído hasta entonces, sino de un único florilegio de sentencias, como bien demostró en 1996 Íñigo Ruiz Arzállus, el de las Auctoritates Aristotelis. ${ }^{25}$ Su uso y abuso en esta parte de $L C$ es similar, aunque en menor escala, al que se hace con el Indice de Petrarca en los actos siguientes tanto de $C L-16$ como de $C L-21 ;{ }^{26}$ la única diferencia en su empleo es que en el caso de los Parui flores las sentencias se emplean solamente como adiciones primeras, antes de llegar a la imprenta, y en lo que se refiere al Índice de Petrarca se recurre a interpolar las paremias antes y después de publicarse la obra por vez primera. En mi edición de $L C$, desconociendo en el momento de su preparación la excelente investigación de Ruiz Arzállus, daba precisamente como añadidos o/y posibles refranes los pasajes que él identifica como pertenecientes a las Auctoritates Aristotelis. ${ }^{27}$

Antonio Sánchez Sánchez Serrano presentó en 1985 una tesis doctoral, publicada tres años después, en la cual defendía que lo que encontró el segundo autor fue una comedia de final feliz con una "redacción seguida, sin división en autos» $\mathrm{y}$ "sustancialmente distinta a La Celestina que conocemos» y» cuya intervención real en la gestación de la obra fue, por tanto, de entidad muy inferior a lo tradicionalmente admitido y concorde [...] con el verdadero significado de la palabra 'acabar' [...]. ${ }^{28}$ Posteriormente precisará, junto a $\mathrm{M}^{\mathrm{a}}$ Remedios Prieto de la Iglesia, que «El 'amigo' modi-

\section{2.- Marciales, II, p. 57.}

23.- «el hecho harto significativo de la existencia de una diferencia profundísima en cuanto a las fuentes utilizadas en el acto primero ¡y principio del segundo! Y los demás actos». Castro Guisasola, F., Observaciones sobre las fuentes literarias de 'La Celestina', Madrid, 1973, Revista de Filología Española, Anejo v, p. 188.

24.- Martín de Riquer, p. 376.

25.- «El mundo intelectual del 'antiguo autor': las Auctoritates Aristotelis en la Celestina primitiva», B.R.A.E., LXXVI (1996); Cuaderno CCLXXIX, pp. 265-284.

26.- Los pasajes de Petrarca están interpolados a CL. Cfr. Cantalapiedra (2001: pp. 54-154)..

27.- Las sentencias estudiadas por Ruiz Arzálluz, mostrando en primer lugar su propia clasificación numérica, se encuentran en los siguientes pasajes de mi edición: a) adiciones manuscritas: 1. (I.10); 2. (I.53); 3. (I.56); 4. (I.65); 6. (I.110, Floresta, p. 1386); 7. (I.134, p. 339, señalo los pasajes añadidos entre I.25 y I.72); 8. (I.142 y I.151, p. 335); 11. (I.158); 12. (I.160); 13. (I.160, p. 339); 15. (I.165); 16. (I. 170); 17. (I.170, Floresta, pp. 1372-3): 19. a y b (II.1, p. 347); 20. (II.4); 21. (II.1-5, p. 347); b) refranes añadidos: 9. (I.153, p. 335); 10. (I.157, p. 339); 14. (I.152); posibles refranes: 5. a y b (I.69), 18. (I.175).

28.- Antonio Sánchez Sánchez-Serrano, Mensaje de 'La Celestina'. Análisis de un proceso de comunicación diferida, Universidad Complutense de Madrid, Colección Tesis doctorales, 1988, pp. 545-547. 
fica, 'acaba' la obra, dándole un desenlace 'amargo', trágico'». ${ }^{29}$ Mediante métodos y vías distintas de estudio y desconociendo mi labor, sus conclusiones corroboran las mías; pues el nuevo rumbo de la obra hacia la tragedia se inicia precisamente en el inicio del acto XIII. Años después, García Valdecasas ofreció una variante al afirmar que el manuscrito contenía los catorce primeros actos, ${ }^{30}$ tesis que defiende a su vez Antonio Bernaldo de Quirós. ${ }^{31} \mathrm{El}$ paso siguiente consistió en dudar de la autoría de Rojas en la creación de $L C$, Joseph Snow y Víctor Infantes, ${ }^{32}$ y «como mucho, es posible que haya participado en su versión definitiva, de ahí la frase aparecida en los acrósticos de que "acabó» la obra»; ${ }^{33}$ resulta pues lógico y congruente que el autor de estas últimas palabras, Canet Vallés, publicara una excelente edición de la Comedia de Calisto y Melibea sin nombre de autor (o autores), aunque bueno será recordar al lector que CL-16 es ya, pese a su título, una Tragicomedia, tal y como nos advierten los paratextos de CL-21 y los primeros lectores de CL-16; y que, según Canet Vallés, «el cambio a 'desastrado' fin tendría lugar en la tradición manuscrita» ${ }^{34}$

Charles B. Faulhaber publicó en 1990 un inédito fragmento manuscrito ${ }^{35}$ del inicio del primer acto de $C L(M p)$, suscitando inmediatamente un gran interés y unos magistrales estudios; unas veces complementarios y

29.- Antonio Sánchez Sánchez-Serrano y Ma Remedios Prieto de la Iglesia, Fernando de Rojas y 'La Celestina', Barcelona, Teide,1991, p. 41; "Sobre la composición de La Celestina y su anónimo 'auctor'», Celestinesca, 33 (2009), pp. 143-171.

30.- José Guillermo García Valdecasas, La adulteración de La Celestina, Madrid, Castalia, 2000.

31.- Antonio Bernaldo de Quirós, «Comentarios a la hipótesis de García Valdecasas sobre la gestación de La Celestina», Espéculo, 30 (2005); «Sobre el papel de Rojas en la elaboración de La Celestina», Lemir, 12 (2008), pp. 325-339; "La Celestina desde el punto de vista escénico. Consecuencias para la atribución de la autoría», Lemir, 13 (2009), pp. 97-108; «El bachiller Fernando de Rojas acabó (y empeoró) la Comedia de Calisto y Melibea», Etiópicas, 5 (2009), pp. 162-184. Ed. Anónimo/Fernando de Rojas, Comedia de Calisto Y Melibea. Hacia la Celestina anterior a Fernando de Rojas, Madrid, Manuscritos, 2010.

32.- Joseph T. Snow, «La problemática autoría de Celestina», Incipit, XXV-XXvi (2005-2006), pp. 537-561. Víctor Infantes, «Los libros 'traýdos y viejos y algunos rotos' que tuvo el bachiller Fernando de Rojas, nombrado autor de la obra llamada Celestina», Bulletin Hispanique, 100 (1998), pp.1-51. El estudio de la biblioteca de Rojas indujo también a Clara Louisa Penney a la duda de que fuera realmente un estudiante el autor de CL. Cfr. The book Called "Celestina" in the Library of the Hispanic Society of America, New York, The Hispanic Society of America, 1954, pp. 8-9.

33.- José Luis Canet Vallés, Comedia de Calisto y Melibea, Valencia, PUV col. Parnaseo, 2011, p. 19. Sobre los acrósticos y los mensajes cifrados sobre el inicio y acabado de la obra véase Cantalapiedra (1979: 193-241, y 1986: 189-224).

$$
\text { 34.- Ob. Cit., p. } 12 .
$$

35.- Charles B. Faulhaber: a) «Celestina de Palacio: Madrid, Biblioteca de Palacio, MS 1520», Celestinesca, 14-2 (1990), pp. 3-39; b) Charles B. Faulhaber, "Celestina de Palacio: Rojas's Holograph Manuscript», Celestinesca, 15-1 (1991), pp. 3-52; c) "MS 1520 de la Biblioteca de Palacio. De los 'papeles del antiguo auctor' a la Comedia de Calisto y Melibea: Fernando de Rojas trabaja su fuente», en Literatura Medieval. Actas do IV Congresso da Associação Hispânica de Literatura Medieval (Lisboa, 1-5 Outubro 1991), Lisboa, Edições Cosmos, 1993, vol. II, pp. 283-287. 
otras veces divergentes, por parte del propio Faulhaber, Botta, ${ }^{36}$ Conde, ${ }^{37}$ García, ${ }^{38}$ Lobera Serrano, ${ }^{39}$ Michael, ${ }^{40}$ Serés, ${ }^{41}$ entre otros. Mp consta únicamente de ocho folios, del 93 al 100, y ha perdido dos (uno entre el f. 95 y el 96, y el otro entre el f. 97 y el f. 98); está compuesto, sigo en esto a Patrizia Botta, de dos partes bien diferenciadas por una gran mancha, por el ancho de la caja de escritura, por la práctica ausencia de márgenes en la caja más estrecha, por la presencia de dos copistas y de distintas tintas, y por las correcciones que realiza la segunda pluma sobre la labor de la primera. Cabe pues distinguir dos subconjuntos textuales, desde el punto de vista material, el de la parte primera $(M p-a)$-f. 94, 95, 96 y 97-, y el posterior $(M p-b)$-f. 93, 98, 99, 100- De las dos hojas desaparecidas, la primera se incluía en el fascículo $M p$-a, y no podemos saber, sin desmontar el manuscrito, a que parte atribuir la segunda hoja perdida. Las ocho hojas del $M p$ son un verdadero jardín de interpretaciones y de variantes textuales. Patrizia Botta ${ }^{42}$ distingue 176 variantes que modifican la extensión del texto —73 adiciones y 103 omisiones - , 41 desplazamientos y 130 sustituciones, que afectan tanto al fascículo $M p$ - $a$ como al $M p$ - $b$; la reorganización de los datos ofrecidos por la citada investigadora en sus apéndices se presenta como sigue:

36.- Patrizia Botta: a) «La Celestina de Palacio en sus aspectos materiales», Boletín de la Real Academia Española, 73 (1993), pp. 25-50 y 347-366; b) «El texto en movimiento (de la Celestina de Palacio a la Celestina posterior), en R. Beltrán y J. L. Canet (eds.), Cinco siglos de Celestina: aportaciones interpretativas, Valencia, Universidad de Valencia, 1997, pp. 135-159.

37.- Juan Carlos Conde: a) «El manuscrito II- 1520 de la Biblioteca de Palacio: un nuevo testimonio del Diálogo de vita beata de Juan de Lucena», La Corónica, $21-2$ (1993), pp. 34-57; b) «El manuscrito II-1520 de la Biblioteca de Palacio y La Celestina: balance y estado de la cuestión", en R. Beltrán y J. L. Canet (eds.), Cinco siglos de Celestina: aportaciones interpretativas, Valencia, Universidad de Valencia, 1997, pp. 161-185.

38.- Michel García: a) "Consideraciones sobre Celestina de Palacio», Celestinesca, 18-1 (1994), pp. 3-16; b) "Apostillas a "Consideraciones sobre Celestina de Palacio», Celestinesca, 18-2 (1994), pp.145-149.

39.- Francisco J. Lobera Serrano, «El Manuscrito 1.520 de Palacio y la tradición impresa de La Celestina», Boletin de la Real Academia Española, 73 (1993), pp. 51-67.

40.- Ian Michael, «La Celestina de Palacio: el redescubrimiento del MS. II-1520 (sign. Ant. 2. A.4) y su procedencia segoviana», Revista de Literatura Medieval, III (1991), pp. 149-171.

41.- Guillermo Serés, "Primeros textos y fortuna editorial (siglos XVI y XVII)», en Fernando de Rojas (y 'antiguo autor'), La Celestina. Tragicomedia de calisto y Melibea, pp. LXXVII, LXXIX, LXXX.

42.- Botta, «el texto en movimiento...», pp. 143-145, y los apéndices: 148-157. 


\begin{tabular}{lcc}
\multicolumn{1}{c}{ apéndices } & $M p-a$ & $M p-b$ \\
\hline 1. Lecciones mejores & 6 & 10 \\
2. Añadidos -A- & 3 & 6 \\
3. Añadidos -B- & 6 & 4 \\
4. Omisiones & 10 & 5 \\
5. Desplazamientos -A & 12 & 7 \\
6. Desplazamientos -B- & f. 95v. 6-7, f. 96r. 22, f. 96v.1 & \\
7. Sustituciones & 23 & 7
\end{tabular}

Todo ello entre raspaduras, tachaduras, variantes redaccionales, anotaciones interlineales y marginales a dos manos, glosas, y un fascículo, $M p-a$, carente de márgenes, lo cual implica información perdida. Todo ello desmonta definitivamente el mito del anónimo primer acto escrupulosamente respetado por el continuador; resulta obvio, por analogía, que los demás actos estuvieron sometidos al mismo tratamiento de modific ción textual. Sabemos además, gracias a los estudios de Lobera Serrano, que el $M p$ no se entronca en la tradición impresa de CL-16 ni de CL-21, pero que se sitúa en la parte alta del stemma ${ }^{43}$ La crítica ha oscilado entre atribuir a $M p$ el carácter de autógrafo de Rojas al de interpretarlo como una de las primeras imitaciones de $L C$, pasando por la idea de que se trata de "los papeles del antiguo autor», esto es del primer acto, o de estos revisados por Rojas. Los aspectos materiales antes citados muestran que no es así, ni es autógrafo, ni son los "papeles» del autor, ni es una imitación, y tampoco es un borrador.

Nótese que es el ulterior $M p-b$ el que introduce los paratextos, únicamente el "Síguese» y el "Argumento general», ${ }^{44}$ en el f. 93v., y no el $M p$ - a como era de esperar; ${ }^{45}$ éste inicia directamente la obra, sin la cruz o la palabra ihesus, y sin el título, ${ }^{46}$ con las palabras de Calisto: "Caljsto. Enesto veo meljbea la grandeza de dios». Esta ausencia de los paratextos en el $M p-a$ —es improbable que el copista de este fascículo se olvidara

43.- Lobera Serrano, 1993, pp. 62-67. José Luis Canet Vallés sitúa también Mp en la parte alta del stemma. Cfr. Comedia de Calisto y Melibea, pp. 146-148.

44.- Con variantes mínimas en relación a las impresas de CL-16 ('delas alcahuetes' y 'desu madre eljsa'), y coincidencias ocasionales en la palabras unidas: delos, delas, enel, della, ala... Estos paratextos de $M p-b$ parecen ser copia de alguna edición de CL-16.

45.- También Patrizia piensa que estas palabras de Calisto indican que el segundo fascículo, $M p$-b, es posterior (1993: 44).

46.- La ausencia del márgen superior nos impide saber con certerza si estos elementos estaban presentes. Pero el texto, que cierra los liminares de $M p-b$, "Calys'to/y melibea/ comjença caljs'to", ausente de las ediciones impresas, parece ser el título del $M p$-a. De ser así, se abriría otra línea de investigación en torno a la biblioteca de Rojas y a su «libro de Calisto», para saber si se trata de «la puta vieja Celestina» o de otra edición perdida con el título de Calisto y Melibea. Cfr. Fernando Cantalapiedra Erostarbe, «Fue tanto breve quanto muy sutil. Los paratextos de La Celestina», eHumanista, 18 (2011). 
de copiar precisamente la primera plana, que ocupa además el verso del folio- y algunas de las correcciones que efectúa en éste el copista de $M p-b$ me llevan a pensar que las copias se realizaron al menos sobre dos modelos diferentes y en tiempos distintos; lo cual implica que el $M p$ - $a$ y el $M p$ - $b$ ocupan dos posiciones distintas en el stemma. En todo caso, estos dos testimonios dan fe de una obra anónima.

La segunda pluma censura, castiga, el primer diálogo de $M p$ - $a$ - «si Dios me diese enel çiel[o la] silla cabe su hijo a su derecha mano» por "sobre sus santos", sin modificar la variante siguiente: "creo no me s[...] / mayor feljçidad» $(M p-a) /$ «no lo ternía por tanta felicidad» $(C L-16)$. Ahora bien, este castigo entra en contradicción con el pasaje anterior:

$$
\begin{aligned}
& \qquad M p-a, \text { f. } 94 \mathrm{r} \\
& \text { los' gloriosos s'antos [...] no } \\
& \text { gozan tanto commo yo }
\end{aligned}
$$

cabe su hijo a su derecha mano creo no me s[ería] / mayor felj̧̧idad ${ }^{46}$ bis

\author{
CL-16, I.3-5 \\ Los gloriosos santos $[\ldots]$ no \\ gozan más que yo \\ sobre sus santos \\ no lo ternía por tanta felicidad»
}

El $M p$ - $a$ sigue en lo referente al gozo y sus comparativos una progresión lógica ascendente —los santos: 'no tanto' $\rightarrow$ el hijo de Dios: 'no mayor'-; el segundo amanuense no cambia el segundo comparativo - 'sobre sus santos [...] no mayor', y las impresas al cambiarlo establecen una clara regresión - 'no más que yo' Ł 'tanta como ellos'; según esto, el saltaparedes quiere gozar menos de lo que ya goza; censura absurda, pues éste considera a Melibea como su Dios, y lo que desea es precisamente estar junto a ella, ascender en la jerarquía celeste. ${ }^{47} \mathrm{El} \mathrm{Mp}$ - $a$ ofrece sin embargo un sintagma correcto allí donde en $C L-16$ resulta confuso, «ny otro' p[oder] njn voluntad umana puede conpljr», pues estas leen "mi», transformando el adverbio de negación en posesivo; pasaje que CL-21 omite al no comprender su sentido.

En cuanto a la posible extensión de los modelos copiados, es evidente que abarca mucho más allá del primer acto, como muestran los paratextos de $M p-b$ y los siguientes ejemplos, los grillos y la vela, tomados tanto del $M p$ - $a$ como del $M p-b$ :

«si pasa por los' perros. Aquello suena sus ladrjdos [...] quando camjna los' grillos' la sigen» (f. 99r, $M p-b$ ).

46 bis.- Coincide con la traducción al italiano (Roma, 1506): 'maggior felicita'. Cfr. Botta (1997: 140).

47.- Pasar de la tercera jerarquía, la de los santos (arcángeles y ángeles), a la primera, la de los serafines o del 'amor ardiente'. 
El último sintagma no aparece en las ediciones impresas de CL. La alusión a los grillos en $M p-b$ no es gratuita, pues Pármeno sigue empleando esta figura con idéntica ironía en el acto vi.37:48

[...] porque no fuercen a la niña [...] Tú irás con ella, Sempronio, que ha temor de los grillos que cantan con lo escuro.

Y que van tras ella cantando. ${ }^{49}$ "No tiene más corazón que un grillo", dice un viejo refrán. ${ }^{50}$ Temor que desmiente después la Trotaconventos ante el propio Pármeno: «no he temor que me fuercen en la calle» (VII.103) -e insiste socarrona en el acto Ix.9: "están aquí dos hombres que me quieren forzar»—, enlazando inmediatamente en palabras de Elicia con la figura de los perros: «El perro ladra. ¿Si viene este diablo de vieja?» (vII.104). No es posible imitar una ausencia en el modelo. Lo mismo puede decirse de una sustitución que aparece en el fascículo $M p-a$ :

$$
M p-a, f .94 \mathrm{v}
$$

c. saca la vela y dexa la tinjebra Acompañar Al triste $\mathrm{y}$ al desdich(")ado la ceguedad.
CL impresas, I.10.

\section{CALISTO.- Cierra la ventana} y dexa la tiniebla acompañar al triste, y al desdichado la ceguedad.

La vela de $M p$ - $a$ asociada a la tristeza tiene su correlato narrativo, temporal y simbólico en el acto XII.60, precisamente tras el deseado encuentro entre Calisto y Melibea, el tan ansiado "alivio de su pena»:

CALISTO. - (60) Cerrad essa puerta, hijos. Y tú, Pármeno, sube una vela arriba.

48.- Cito por el sistema de numeración de pasajes seguido en las ediciones de LC de Miguel Marciales y de Fernando Cantalapiedra.

49.- «¡ O, qué gasajo es oír / el sonido de los grillos / y el tañer los caramillos!». Juan del Encina, Égloga de Mingo, Gil y Pascuala, ed. de Miguel Ángel Pérez Priego, Cátedra, Madrid, 1991, p. 183.

"Sabes sabes el modorro / alla donde anda a grillos / burlanle los moçalvillos / que andan con él en el corro / armanle mil guadramañas / vno le saca las pestañas / otro le pela los cabellos / assí se pierde tras ellos / metido por las cabañas». "Que anda a grillos, que anda en alguna negociación de que ni se espera fruto ni effecto". Coplas de Mingo Revulgo glosadas por Fernando del Pulgar, Salamanca, Juan de Porras ¿1498?, f. bij.

50.- Anónimo, Adagios, Proverbios o sentencias varias (en romance y en latín), Ms., s. XVI, entre 1501 y 1600. Signatura Mss / 4502. Biblioteca Nacional de Madrid, f. 18.

Grillos dio lugar a juegos de palabras entre 'insecto' y 'grilletes'. Quevedo: «Andaba a caza de gangas, / y grillos vine a cazar, / Que en mí cantan como haza / Las noches de por San Juan.», "Los diez años de mi vida / Los he vivido hacia atrás, / Con más grillos que el verano, / Cadenas que el Escorial». Francisco de Quevedo, Poesía varia, ed. de James O. Crosby, Madrid, Cátedra, 1981, pp. 298 y 322. 
La primera vela, como ya he explicado en otro lugar, ${ }^{51}$ evita además algunos desajustes temporales de la obra al situar su inicio un poco antes del amanecer. La sustitución de la «vela» por la «ventana» obedece a la posterior incorporación en $L C$ de la primera escena de la huerta, que es evidentemente diurna (o soñada, pero añadida sin ton ni son). En el $M p-a$ este primer diálogo carece de deícticos y referentes espacio-temporales, no sabemos dónde ni cuándo tiene lugar y está aislado escénicamente de la secuencia siguiente. El argumentista de $M p-b$ tampoco lo sabe pues explica que «dispuso el adversa fortuna lugar oportuno, donde ala presençia de Calisto se presentó la deseada Melibea»; 'lugar oprtuno' es calco evidente de ese 'convenjente lugar' que tiene escrito ante sus narices. Aunque la segunda pluma censura, castiga, el texto inicial de $M p$ - $a$ no modifica la "vela» por la "ventana», cosa que sí hacen las ediciones impresas. En el argumento o sumario del primer acto de CL-16 se procura subsanar estas lagunas, precisando el lugar y el motivo del encuentro: «Entrando Calisto [en] una huerta empós d'un falcón suyo falló y a Melibea [...] fue para su casa muy sangustiado", pero no modifica el texto contradictorio del argumento de $M p-b$. Lo que implica que el $M p$ es anterior a CL-16, que elimina la contradicción temporal, al transformar en diurno el diálogo entre Calisto y Sempronio, y posterior a otros posibles manuscritos carentes del diálogo en la huerta.

Las ediciones impresas de CL omiten en I.8 la palabra "mientes», que Calisto dirige directamente a Sempronio. La mentira es una figura discursiva recurrente en la obra (I.36, 45, 58, 109; IV.86, vI.20, 21, 41, VII.32, IX.4...), pero su uso como acusación directa ante la propia persona, acompañada de insulto y en un entorno semio-narrativo parecido se da en el octavo acto:

$$
\text { Mp-a f. 94v., I.8 }
$$

c. [...] senbronjo. donde esta este maldito. [...] mientes.

\section{VIII.37}

CALISTO.- Di, Sempronio, ¿miente esse desvariado, que me haze creer que es de día?

"Asy los diablos te lieven" dice Calisto en $M p$ - $a$, y le responde el criado en la CL impresa "iTrobará el diablo!», el insulto a los criados — maldito el uno, desvariado el otro-, la cama, la dualidad simbólica noche/día del enamorado que rechaza la luz se encuentran presentes en estos dos pasajes, que además se inician o cierran con la música y las canciones del mancebo. En la explicación de Sempronio en I.8 aparece una redacción en $M p-a$ algo distinta y superior a las ediciones impresas:

51.- Fernando Cantalapiedra Erostarbe, «Fue tanto breve quanto muy sutil. Los paratextos de La Celestina», eHumanista, 18 (2011). 


$$
M p-a, \text { f. 94v. I.8 }
$$

debatiose el girifalte, questava colgado dellalcandara \& vinele Aendereçar
CL-16 1.8

Abatióse el girifalte y vínele $[a]^{51-1}$ endereçar en el alcándara.

Las aves de cetrería se 'abaten' sobre sus presas y se 'debaten' en sus alcándaras:

Otro sy te digo que delas tales caydas $\bigcirc$ debateduras de alcandara \& dela mano de mal caçador Resçibe el falcon gran quebrantamjento. [...] \& aun te digo que la batedura o (t)[d]erramadura del alcandara es much(n)o peor que la dela mano por que el falcon non es tan ligero en su debatir como el astor E quando se debate non se puede tornar a la vara [...] Otro ssy enlas debateduras quel falcon faze. enel alcandara. ${ }^{52}$

El cambio léxico y la omisión de la explicación, "questava colgado», orienta el texto impreso hacia la poesía amorosa, hacia la presa de amor, en un intento de hacernos olvidar que si el gerifalte está en la sala con el criado no estaba entonces en la huerta de Melibea, y menos de noche. De hecho, nada indica en el $M p$ que así fuera pues carece del sumario del primer acto ( $y$, por supuesto, de los otros quince). La reacción de Calisto a las palabras de Sempronio ofrece dos redacciones distintas:

$$
\text { Mp-a f. 94v. }
$$

As'y los diablos te ljeven As'y muerte desastrada mueras As'y perpetuo tengas el tormento que yo traygo ${ }^{52-1}$ ques peor commo dizes' verdad.

$$
\text { CL, I.9 }
$$

¡Assí los diablos te ganen! ¡Assí [por infortunio arrebatado perezcas, o] perpetuo intollerable tormento consigas, el qual en grado incomparable[mente] a la penosa y desastrada muerte que espero traspassa ${ }^{52-2 !}$

51-1.- Burgos 1499 y Toledo 1500 omiten la preposición «a», que aparece en la edición sevillana de 1501.

52.- Pero López de Ayala, Libro de la caça de las aves, ed. de José Manuel Fradejas Rueda, Madison, Hispanic Seminary of Medieval Studies, 1995, f. 65v.

52-1.- Michel García lee "guyso» y no "traygo», como ha leído Faulhaber. El error de interpretación de ese verbo hace incomprensible el último elemento de la frase. Opino que no es así si se lee "guyso». En "Consideraciones sobre Celestina de Palacio», Celestinesca, 18.1 (1994), p. 6, n. 9. No obstante, Juan Carlos Conde demuestra que «el manuscrito lee, indudablemente, traygo. En «El manuscrito de la Biblioteca de Palacio y Celestina», ob. cit, pp. 180-181.

52-2.- Toledo 1500: 'así', Zaragoza 1507: 'incomparablemente - traspasse'. 
Las dos lecturas son complejas; en $M p$-a sobra el sintagma "ques peor commo dizes' verdad", o hay algo omitido, puesto que nada ha dicho todavía el criado sobre el particular y nada puede compararse en ese momento del diálogo; se modifican los verbos del pasaje: lyeven / ganen, mueras / perezcas, tengas / consigas... La lección 'ljeven' es más acorde con el pasaje I.12-13: "¡Ve con el diablo!»; nótese asimismo que en las ediciones impresas de $L C$ lo usual es el engarce semántico diablo / verbo de movimiento:

\begin{abstract}
"iAllá yrás con el diablo» (II.28), «Por aquí anda el diablo aparejando oportunidad» (Iv.27), «iVálala el diablo, haldear que trae! (v.6), «iDe qué gana va el diablo!» (vi.42), "¿Si viene este diablo de vieja?» (VII.104), «ivaya el diablo para ruyn'! (viII.28), "iAllá yrás con el diablo tú y malos años! (vIII.48).
\end{abstract}

La respuesta del criado difiere según las versiones

$$
M p-a, \text { f. 94v. }
$$$$
\text { CL, I.12-13. }
$$

No puede ser segund pienso yr No creo, según pienso, yr conmigo el que contigo queda . conmigo el que contigo queda.

En CL los dos primeros sintagmas son prácticamente sinónimos y reiterativos: "no creo / no pienso", mientras que el primer segmento de $M p-a$ es un aserto categórico. Los tres anhelos indicados por la interjección "así» en $M p$-a quedan reducidos a dos en CL al sustituir el tercer elemento de la serie por la conjunción disyuntiva "O»; las impresas omiten además el "tormento", de origen pasional, que padece en ese momento Calisto y que desea al criado. Con la «muerte» ocurre otro tanto, se desea para el criado en $M p$-a y en $C L$ se añade este mismo anhelo para el propio de Calisto, invirtiendo en este proceso el orden del sintagma: muerte desastrada / desastrada muerte, y el sujeto personal: tú / yo. Estos cambios redaccionales intentan dar una cierta congruencia a las variaciones que se efectúan en el pasaje 1.11-12, uno de los más complejos de la $C L$ y que ha producido una amplia y variada crítica textual..$^{53}$ Estas son las dos versiones: 
$M p-a$, f. 94v.

c saca la vela y dexa la tinjebra Aconpañar Al triste y al desdich( )ado la ceguedad . mjs tristes pensamjentos' non son dignos' de luz . o bien aventurada muerte aquella que desead(j)a . alos Aflitos viene + . S. que cosa es'.

\footnotetext{
$+[\wedge$ sentirias mi mal / o piedad de seleuco $][\ldots]^{53-1}$
}

CL-16, I.11-12

CALISTO.- Cierra la ventana $y$ dexa la teniebla ${ }^{53-2}$ acompañar al triste, y al desdichado la ceguedad. Mis pensamientos tristes no son dignos de luz. ${ }^{*} \bigcirc$ bienaventurada muerte aquella que deseada a los afligido ${ }^{53-3}$ viene!

(11) [¡O! ¡si viniessedes ${ }^{53-4}$ agora Eras y Crato, ${ }^{53-5}$ médicos, sentiríades mi mal $¡ \bigcirc$ piedad de silencio, ${ }^{53-6}$ inspira en el plebérico ${ }^{53-7}$ coraçón, porque sin esperança de salud no embíe el espíritu perdido con el desastrado Píramo ${ }^{53-8}$ y de la desdichada Tisbe!]

SEMPRONIO.- (12) ¿Qué cosa es?

Botta $^{54}$ indica que el añadido marginal, truncado en su inicio y en su final por la guillotina del encuadernador, es una corrección de la segunda mano, la que copia $M p-b$. ¿Olvidó el primer copista estas paremias, que ocupan varias líneas, o no estaban en su modelo o estaba éste en un estado ilegible? El caso es que la ediciones impresas tuvieron también serias dificultades a la hora de interpretar este paso en sus modelos manuscritos, ${ }^{55}$ y llama también la atención que por vez primera en la obra nos encontramos ante un ramillete de tres paremias. Todo parece indicar

53-1.- Faulhaber (1990:15): «una cruz sobre la línea remitía a otra en la margen inferior, ya cortada por el encuadernador, para indicar la adición, también cortada».

53-2.- C: 'tenebla', D: 'tiniebla'.

53-3.- C: 'aflegidos'.

53-4.- B: vinissedes.

53-5.- CL-21: 'Crato y Galieno'. Sal., 1570: 'Erasístrato y Galieno'.

53-6.- CL-21: 'celeuco'. F: 'celestial'. Valencia 1529: 'Seleuco'. Salamanca 1570: 'seleucal'.

53-7.- F, Salamanca 1570: 'en el Pleberio coraçón'.

53-8.- D: 'pirmano'.

54.- 1993, p. 37.

55.- El ms. de Celestina Comentada se inicia en el f. $14 \mathrm{r}$ con lo que semeja ser la glosa a la sentencia de Boecio, copia a continuación el párrafo donde se halla la frase « $\bigcirc$ si viniessedes agora Crato y Galieno sintiriades mi mal? O piedad celestial espira en el pleberico coraçon", y glosa sobre el primero: «creo que ha de dezir Craton que fue medico». Ed. de Louise FothergillPayne, Enrique Fernández Rivera y Peter Fothergill-Payne, Universidad de Salamanca, 2002. 
que se trata de notas o glosas marginales que acaban, en un momento u otro, interpoladas a la obra, ${ }^{56}$ claro ejemplo de las llamadas adiciones primeras. La sentencia boeciana - la primera, del pasaje y de la obratomada directamente de las Auctoritates Aristotelis, ${ }^{57}$ no encaja con la increpación de Calisto en $\mathrm{Mp}$-a donde lo que éste desea es la muerte de Sempronio, lo que indicaría que la sentencia era ya un añadido marginal en el modelo de $M p$ - $a$ o en el de $M p$ - $b$, imposible saberlo. El ejemplo marginal añadido por el segundo amanuense está incompleto, aunque la presencia de un verbo en segunda persona del singular y la lección correcta del nombre propio de Seleuco permite restaurar el lugar común y la lectura correcta en las ediciones impresas:
"[O si viniéssedes agora Erasístrato, médico] sentirías mi mal / o piedad de Seleuco». ${ }^{58}$

Esta historia conocidísima en el medievo está tomada directamente de las Vidas paralelas de Plutarco, ${ }^{59}$ el único que cita únicamente el nombre del médico Erasístrato. Su inclusión en la $C L$ origina una serie de paralelismos sin sentido ni desarrollo narrativo: Calisto / Antíoco, Melibea / Estratónice, Pleberio / Seleuco. Es decir, Melibea es la madrastra de Calisto y Pleberio el padre de éste y marido de la buena moza; lo que conduce a las confusas palabras de Melibea en la extraña escena anterior «en el yljçi-

56.- Michel García piensa lo mismo: «¿Cómo se le ha podido escapar al amanuense una frase tan larga? [...] Resultaría más lógico pensar que dicha frase no figuraba en el modelo que el primer copista siguió y fue añadida por el segundo copista a partir de otra versión». En "Apostillas a 'Consideraciones sobre Celestina de Palacio'», Celestinesca, 18-2 (1994), p. 147. De hecho, Patrizia Botta termina reconociendo este fenómeno en uno de sus artículos: «Lo que nos enseña la historia textual de $L C$ es que [...] por mucho tiempo ha circulado anónima, en distintas versiones, que quizá ha tenido una vida oral-teatral, y que, a medida en que se va transmitiendo o editando, sufre retoques, adiciones y supresiones de qualquiera, como si fuese un romance de tradición oral, cuyo autor es un autor-legión». En «El texto en movimiento (de la Celestina de Palacio a La Celestina posterior)", art. cit., p. 147. Michael Gerli señala varios casos de este tipo de incorporaciones de los comentarios marginales al texto literario en $E l$ Corbacho, ob. cit., pp. 126, 220-221.

57.- Ruiz Arzállus (1996: 271). Castro Guisasola cita asimismo a Pérez de Guzmán, Floresta de Philósofos, 47, 4 (1924: 102).

58.- Melibea repite la fórmula en $\mathrm{x} .3:$ « $\mathrm{O}$, si ya viniesses con aquella medianera de mi salud!». Pasaje que señalo en mi edición como posible adición primera.

59.- Plutarco, Vidas paralelas, trad. de Alfonso de Palencia, cap. xxxviII, Vida de Demetrio. Sevilla, 1491, f. $242 \mathrm{v}$.

Valerio Máximo narra esta historia citando al «astrólogo Leptinio o, como otros aseguran [al] médico Erasístrato» en Dichos y hechos memorables, v.VII, De los extraños. Curiosamente la edición de Zaragoza de 1495 (Ugo de Urries) lee mal los nombres: «este mal de tristeza fue descobierto por la prudencia de un mathemático nombrado Lepucrens o según otros Trasistrato muy gran phýsico", f. CLXXII; en consecuencia, no tenemos la certeza de que en el Mp-a se escribiera realmente "Erasístrato, médico». Sobre la evolución de esta historia es de particular interés el estudio de Bienvenido Morros «La difusión de un diagnóstico de amor desde la antigüedad a la época moderna», BRAE, LXXIX (1999), pp. 93-150. 
to Amor comunjicar su deleyte» ( $M p$, I.7) y las convierte en un chiste; la agitación e increpaciones de Calisto no se corresponden con la prosternación y mutismo de Antíoco; pues nada tienen en común las dos historias. Si en la primera sentencia boeciana Calisto implora la bienaventurada muerte, que antes se deseaba para el criado, en el ejemplo de Antíoco se solicita el remedio de amor. El latinismo "plebérico coraçón» en las ediciones impresas no puede entenderse pues no se ha citado todavía en la obra, sí en el argumento general ya copiado en $M p-b$, el nombre del padre o marido de Melibea, pero sirve al menos de confuso enlace con el tercer exemplum, ausente también por las causas que fueren en el $M p$, el de Píramo y Tisbe ${ }^{60}$ cuyo trágico y desafortunado final es antitético con el feliz desenlace de Antíoco y Estratónice del ejemplo anterior. ¿¿De quién es y qué pinta en este paso "el espíritu perdido»? ¿Del "triste y desdichado» Calisto? ${ }^{21}$ Parece que se están recordando las palabras de Seleuco:

"y dixo que aquel era su fijo en quien estava puesto todo su estado y reyno, y el espíritu de su vida [...] y que si le perdiesse no lo quedava otra cosa sino la muerte, que él dende en adelante avría de cobdiçiar». ${ }^{6}$

Se reitera el adjetivo ya mencionado, en el sentido de 'desventurado': muerte desastrada $(M p-a)$ / desastrada muerte / desastrado Píramo (CL). McGrady ${ }^{63}$ defiende que Fernando de Rojas modificó el ejemplo de Erasístrato, borró las huellas del presagio de un final feliz, e introdujo la historia de Píramo, que no aparece en el $M p$, como trágico agüero y nuevo rumbo de la obra. Pero no hay modo de demostrar que la segunda alusión estuviese o no estuviese en los márgenes del manuscrito, y mucho menos de saber con certeza quien fue el artífice de su inclusión o exclusión, aunque resulta evidente que la obra impresa modificó la manuscrita en su proceso de transformación de su género literario y de alargamiento, e incorporando las glosas y comentarios marginales. En fin, los augurios son mucho más sibilinos y no se muestran nunca tan claros y evidentes como en este caso.

60.- El Comentador cita a Ovidio, Metamorfosis, Iv, al glosador de los Triunfos de Petrarca, Triunfo de Amor, y el libro I, diál. 69 de Próspera Fortuna (De los agradables amores). No obstante era un lugar común, citado por ejemplo por Juan del Encina, Gómez Manrique, Alfonso x (General estoria), Fernando de la Torre, Diego de san Pedro, Juan de Mena, Juan de Cuenca, Pero Díaz de Toledo, Luis de Lucena...

61.- Calisto se acuerda de su espíritu en I. 27: «Por cierto, si el de purgatorio es tal, más querría que mi espíritu fuesse con los de los brutos animales, que por medio de aquel yr a la gloria de los santos». No precisa la dualidad espíritu / cuerpo hasta el acto XIII.2: «trabajé con el cuerpo y persona, y holgué con el espíritu y sentido la passada noche».

62.- Plutarco, 1491, p. 243.

63.- Mc Grady, "The Studies on the Text of the Celestina», Romance Philology, XIVIII (1994), pp. 1-21. 
Celestina comentada interpreta «en el coraçón de Pleberio padre de Melibea e puédelo dessear para que le diesse a su hija Melibea». ${ }^{64}$ Cejador y Frauca propone la lectura: "En el corazón de Melibea, hija de Pleberio» (I, 36). Miguel Garci-Gómez ${ }^{65}$ lo interpreta como "plebeyo corazón [de Calisto]» y deriva el nombre de Pleberio de este adjetivo; Enrique Fernández Rivera ${ }^{66}$ propone en un razonadísimo estudio la lectura "pletórico corazón", en su acepción médica de plétora, lo que permite contemplar en el diálogo un satírico debate entre las escuelas médicas de Erasístrato y Galeno. De ser así, el «espíritu perdido» del enfermo de amores sería el pneuma, que acompaña a la sangre en el sistema vascular. Ottavio Di Camillo reflexiona sobre un "frenético corazón». ${ }^{67}$ No obstante lo dicho, lo más sencillo es buscar la solución a un problema textual dentro de la propia obra. Calisto emplea una fórmula similar — sufijo -ico con valor preposicional «de» pertenencia, aplicado a nombre propio y enlazado con el motivo del amor filial - en otro ejemplo literario que cita en vi.34-35:

(34) De cierto creo, si nuestra edad alcançara aquellos passados Eneas y Dido, no trabajara tanto Venus para atraer a su hijo el amor de Elisa, haziendo tomar a Cupido Ascánica forma para la engañar; antes por evitar prolixidad, pusiera a ti por medianera. (35) Agora doy por bien empleada mi muerte, puesta en tales manos, y creeré que si mi desseo no oviere effecto, qual querría, que no se pudo obrar más, según natura, en mi salud.

Los dos pasos son simétricos y obedecen a la misma línea de pensamiento. Nos encontramos ante varios elementos comunes: 1) los temas de la salud de amor y de la muerte («bienaventurada / bien empleada»); 2) los ejemplos de «tusca Adeleta» y de "Píramo y Tisbe»; 3) el racimo de paremias, la presencia de Petrarca, segura en este caso, probable en $\mathrm{Mp}$ a; 4) la concordancia de referencias latinas, Ovidio y Virgilio; 5) la alusión a «el amor de Elisa» es un eco de las palabras de Sempronio en I.13:

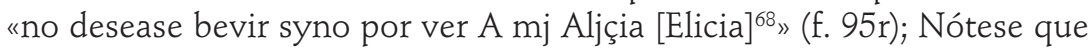
las variantes de los nombres propios van siempre en el mismo sentido:

64.- Edición de Louise Fothergill-Payne, Enrique Fernández Rivera y Peter Fothergill-Payne, Salamanca, Universidad de Salamanca, 2002, p. 11, glosa 10.

65.- «Sobre el plebérico coraçón de Calisto y la razón de Pleberio», en <http://mgarci.aas. duke.edu/celestina/CELESTINA/ENSA/PLEBERIO.HTM>.

66.- «El plebérico corazón, Erasístrato y la plétora», Celestinesca, 39 (2009), pp. 71-85.

67.- «When and where was the firts act of La Celestina composed? A reconsideration» en Devid Paolini (coord.), "De ninguna cosa es alegre posesión sin compañia". Estudios celestinescos y medievales en honor del profesor Joseph Thomas Snow, New York, Hispanic Seminary of medieval Studies, 2010, 1 vol. pp. 91-157.

68.- CL: Elicia. 
'elysa' / Alisa ( $M p-b)$, Aljçia / Elicia ( $M p$-a), Elisa ${ }^{69}$ (Dido) en la presente adición primera. 6) Celestina ocupa ahora el lugar del médico Erasístrato. Este pasaje de vi.33-35 lo señalé como adición primera en mi edición. ${ }^{70}$ Por lo tanto, creo que este ramo de lugares comunes de $M p$-a está asimismo injertado en la obra. Junto a estas formas, 'plebérico, ascánica', los estudiosos suelen trae a colación los sintagmas "éthnicos montes (III.40), «tribunicia constitución» (XIvT.37) y "carro phebeo» (O.P. 6.1); estos dos últimos ejemplos son el primero un añadido en $C L-21$, y el segundo un paratexto de Proaza. El primer sintagma citado se encuentra en la escena del conjuro de Celestina muy ampliado en CL-21 y con todas las trazas de ser una escena ajena a la comedia terenciana de CL-12. Tengo la sospecha de que el segundo amanuense que escribe 'elysa' en el argumento está asociando la reina Dido con la madre de Melibea, y que es responsable de, al menos, la adición primera vi.33-35.

La pregunta de Sempronio «¿Qué cosa es?», equivalente a ¿qué te pasa?, ¿Qué te ocurre?, en singular se refiere única y exclusivamente a la tristeza manifestada por Calisto, al mal de amores, y no a todo lo demás:

c . saca la vela y dexa la tinjebra Aconpañar Al triste y al desdich( )ado la ceguedad . mjs tristes pensamjentos' non son dignos' de luz [...]. S. que cosa es'.

En su respuesta, Calisto reincide en el uso de la figura de la muerte

$$
M p-a, \text { f. 94v }
$$

c. vete de Ay no me hables s'y no quiça Ante's' que venga la muerte quespero mjs manos' cabsaran tu Arebatada fyn.

$$
\text { CL-16, I.12 }
$$

CALISTO.- ¡Véte de aý! No me fables; si no, quiçá ante del tiempo de mi raviosa muerte, mis manos causarán tu arrebata $[\mathrm{d}] \mathrm{o}^{70-1}$ fin

Mp-a sigue la pauta 'bien aventurada muerte' / 'muerte quespero', las ediciones impresas transforman el segundo sintagma en 'raviosa muerte', introduciendo un valor axiológico negativo, violento y reiterativo: «raviosa muerte / arrebatado fin", y modifica el aspecto temporal; mientras que en CL-21, al omitir el posesivo, atribuye este sintagma al criado; de modo que las dos muertes se reducen a una, la de Sempronio.

69.- Valencia 1514 lee Eliza. La traducción italiana de 1506 coincide con el Mp al leer Aliçia y Elisa. Cfr. Botta (1997: 140), que cita la tesis de Carla Simone: La prima traduzione italiana della "Celestina" de i suori rapporti con la edizioni primitive in lingua spagnola (Univ. De Roma 1991, dir. E.Scoles).

70.- Ed. cit., I, pp. 37-38, II, p. 452; III, p. 1500. Cfr. Marciales también indica una adición primera en este lugar, II, p. 111.

70-1.- Burgos 1499: 'arrebatato'. Zaragoza 1507: 'de rabiosa muerte'. 
El pasaje I.41-42 es sin duda uno de los más estudiados por la crítica celestinesca pues plantea varios puntos de interés filológico. También en este caso el $\mathrm{Mp}$ - $\mathrm{a}$ brinda algunas variantes, aunque no resuelve los problemas textuales:

$$
M p-a, \text { f. } 96 \mathrm{r}
$$

[Falta el folio anterior]

cons'tituydas'. se sometieronAlos pech( )os y Resoll[*os] de viles' y $\left({ }^{\wedge} \tan\right.$ pres'tes') [^canpestres] azemjleros' y algunas alas' brutas' Anjmaljas' . no as leydo de pas'ypa conel to[ $\left.{ }^{*} \mathrm{ro}\right]$ y mjreua ${ }^{70-2}$ conel can.$\left({ }^{\wedge} S\right)$. C. no lo creo habljllas' s'o[*n]. S . lo de tu aguela conel xjmjo fue habljlla tes[*tigo] es el $\operatorname{cuch}(\sim)$ illo de tu Aguelo caljsto . c. maldito [*sea] este nec'io que porradas' dize .

$$
\text { CL-16, I.41-42 }
$$

SEMPRONIO.- (41) Dixe que tú, que tienes más coraçón que Nembrot ni Alexandre, desesperas de alcançar una muger; muchas de las quales, en grandes estados constituýdas, se sometieron a los pechos y ressollos de viles azemileros, y otras $^{70-3}$ a brutos animales. (42) ¿No has leýdo de Pasife con el toro, de Minerva con el can? CALISTO.- No lo creo, hablillas son.

SEMPRONIO.- Lo de tu abuela con el ximio, ¿fablilla fue? Testigo $^{70-4}$ es el cuchillo de tu abuelo .

CALISTO.- ¡Maldito sea este necio, y qué porradas dize!

Falta el folio anterior en el $M p-a$ y se reinicia con la palabra "cons'tituydas»; el segundo amanuense cambia (^tan pres'tes') por [^ ${ }^{\wedge}$ canpestres] dando por bueno el resto del pasaje. Si el mito de «Pasife con el toro» figura en muchos textos medievales y no resulta problemático el resto del discurso de Sempronio plantea serias dudas en lo referente a 1) «Minerva con el can», 2) «Abuela con el ximio», y 3) «el cuchillo de tu abuelo». Sobre el primer sintagma se han propuesto las siguientes soluciones: 1) Minerva con Vulcan(o), Otis H. Green; ${ }^{71}$ 2) error intencionado, B. Russell Thompson; ${ }^{72}$ 3) de la moza [Glauca] de Minerva con el can, 4)

70-2.- «El texto dice 'mirenua' con señal de nasalización, que podría interpretarse como 'Minerva' con una metátesis de ' $r$ ' y ' $v$ '». Michel Garcia, "Consideraciones sobre Celestina de Palacio", Celestinesca, 18-1 (1994), p. 6, n. 7.

70-3.- Toledo 1500: 'otros'.

70-4.- Toledo 1500: 'hablilla', 'testigos'.

71.- «Minerva con el can», Nueva Revista de Filología Hispánica, VII (1953), pp. 470-74. José Manuel Fradejas rechaza la lectura Vulcan(o) y "acept[a] la lectio dificilion,, Celestinesca, 17-1 (1993), pp. 47-56.

72.- «Misogyny and Misprint in La Celestina, Acto I», Celestinesca, 1-2 (1977), pp. 21-28. 
de mi nuera con el can, Miguel Marciales; ${ }^{73} 5$ ) Minos con el can [sinécdoque de Escila], Isabel Lozano-Renieblas; ${ }^{74}$ 6) Semiramis con el caballo, Alberto Blecua. ${ }^{75}$

El dios Vulcano / Hefesto no es ni animal ni acemilero, aunque sea deforme y de su semen en contacto con la tierra naciera Erictonio, adoptado por Minerva /Atenea. La tercera propuesta se basa en una pérdida de texto y hace más confuso aún el sentido; la cuarta solución introduce una variante familiar que no existe en la obra. La quinta lectura modifica el sexo del sujeto de deseo e introduce al esposo de Pasífae, a quien se atribuye la invención de la pederastia ${ }^{76}$ la sinécdoque de Escila exige canes en plural, pues eran seis los que llevaba Escila en las ingles, y ya puestos se pudiera pensar en el perro, que nunca dejaba escapar la presa, que Procris exigió a Minos a cambio de librarlo de los efectos de la maldición de su esposa Pasífae según el cual de su cuerpo salían las serpientes y escorpiones que mataban a las mujeres con las que él yacía. La propuesta de Alberto Blecua implica un cambio radical de sujetos, ni Minerva ni el can, y una constante evolución paleográfica en la compleja transmisión manuscrita de la obra. Puestos a cambiar el "can» por el 'caballo' se hubiera podido pensar, por ejemplo, en el de Troya:

E las donzellas non casadas se maravillavan de aquel estraño presente de Minerba e de la grandez del cavallo estavan atónitas, siquiere turbadas. ${ }^{77}$

En ambos casos, la vaca y el caballo son artefactos engañosos y contienen humanos en su interior. La solución, si existe, debe ser mucho más sencilla. En esta escena, Sempronio está aplicando a Calisto la terapia contra el mal de amores: ${ }^{78}$ música, misoginia feroz y risa. Estos dos últimos remedios se presentan en las disquisiciones a la luz de las vela así:

73.- Ob. cit., I. 112-115 y II, 25.

74.- "Minerva con el can», Celestinesca, 15-1 (1991), pp. 75-78.

75.- «Minerva con el can o los falsos problemas filológicos», Revista de Literatura Medieval, 14 (2002), pp. 37-46.

76.- Cfr. Pierre Grimal. Diccionario de mitología griega y romana, Paidós, Barcelona, 1991, p. 359.

77.- Enrique de Villena, Traducción y glosas de La Eneida, Libros I-III, ed. de Pedro M. Cátedra, Madrid, Turner Libros, 1994, p. 253.

78.- Sobre el mal de amores es de obligado estudio el libro de Marcelino V. Amasuno, Sobre la Aegritudo Amoris y otras cuestiones fisiátricas en 'La Celestina', Madrid, CSIC, Anejos de la Revista de Filología Española, 2005. 


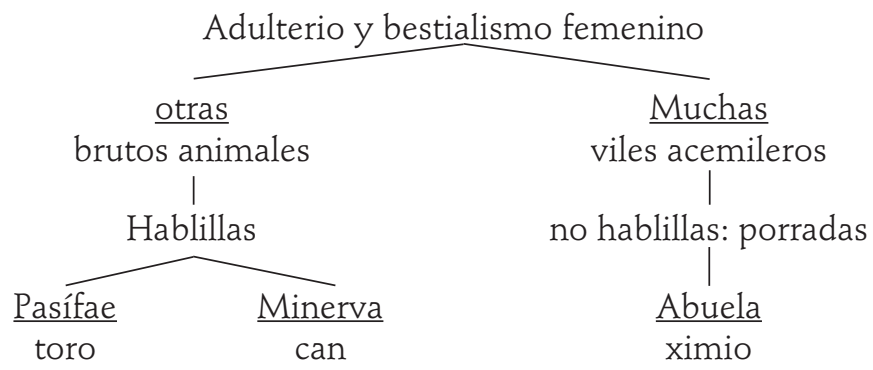

Minerva, ejemplo de sabiduría y virginidad, es entre otras muchas cosas la deesa sanadora y diosa de los oficios femeninos del hilado, de la lana y del tinte, lo cual encaja con la Labrandera y con las tenerías de $L C$; su entronque en el diagrama en la rama de las «hablillas», de las fábulas, mentiras y chistes, la sitúa casi fuera del campo mitológico y en transición hacia lo humano, hacia «la abuela» del sintagma siguiente. Esto nos conduce hacia el famoso debate oratorio entre Démades y Demóstenes narrado por Plutarco en estos términos:

algunas vezes usava de burlas. Como le acaesció quando dixo Démades: "De Demósthenes, la puerca se iura por Minerva». Dixo Demósthenes: «Esta Minerva agora fue tomada en adulterio [en Colito]. ${ }^{79}$

Esto es, «Esa Atenea / Minerva hace poco que en Colito fue sorprendida en flagrante adulterio». ${ }^{80}$ Colito era un barrio popular ateniense y de allí era su maestro Platón. El Corpus Paroemiographorum graecorum ${ }^{81}$ recoge las paremias: «Comparar a Atenea con un gato», «Un cerdo rivalizando con Atenea", el cual pasó a la cultura latina como Minervam sus docet, "un cerdo enseña a Minerva'; 82 "A Tritogenia le ha salido un hijo». ${ }^{83}$ Sin entrar en la

79.- Plutarco, Vidas paralelas, Demóstenes, XI, trad. de Alonso de Palencia, Sevilla, 1491, f. 209 .

He aquí otro ejemplo tomado de la poesía burlesca: «Dos años en Salamanca / me amancebe con Minerua, / que por esso no soy necio, / sino es que el alma me mienta. / Vn orinal de las Musas / se derramo en mi cabeça, / cogido por alambique/ cuando estauan con la regla». Anónimo, Segunda parte del Romancero general y Flor de diversa poesía recopilados por Miguel de Madrigal (1605), ed. de Joaquín de Entrambasaguas, Madrid, CSIC, (1948), t. I, p. 93 . Sobre la alusión a "la regla» téngase en consideración que "Athena [es] vn emplastro llamado minerua» (Fontecha, Diez privilegios para mujeres preñadas, ed. de Ma Purificación Zabía Lasala, Madrid, Arco Libros, 1999, p. 28).

80.- Plutarco, Vidas Paralelas, ed. de José Alsina, Barcelona, Planeta, 1990, p. 665.

81.- Editado por Leutsch y Schneidewin, Gotinga (1839 y 1851); reeditada por George Olms en 1965.

82.- V. J. Herrero Llorente, Diccionario de frases y expresiones latinas, Madrid, Gredos, 1992, p. 262.

83.- Sobre Atenea y las paremias véase el estudio de Enrique Benítez Rodríguez, «Atenea en el Corpus Paroemiographorum Graecorum», en Paremia, 7 (1998), pp. 121-128. 
explicación de estas paremias, se puede constatar que el humor grecolatino establece relaciones entre Minerva, los animales y la maternidad. Sempronio realiza la misma operación semántica que Demóstenes, mantiene el nombre propio y cambia de persona; usa el homónimo conservando el lexema Minerva y sustituyendo su semema 'diosa virgen' por el de 'humana adúltera'; el oxímoron virgen / adúltera es un chiste que permite la transición entre Pasífae y la abuela de Calisto. Recuérdese que, según Esquines y Plutarco, Demóstenes era el »hijo bastardo de Demóstenes el cuchillero», ${ }^{84}$ lo cual nos lleva al 'cuchillo del abuelo Calisto', mientras que el chiste anterior de Sempronio sobre el "pecado de Sodoma» (I.38) recuerda la homosexualidad de Demóstenes, el Bátalo, de quien Esquines decía «el que ninguna parte de su cuerpo tiene sin poner en venta, ni siquiera de donde emite la voz»; ${ }^{85}$ ambos oradores usaban de la palabra mono, desleal, engañoso, ladrón, para insultarse entre ellos, lo que nos acerca al ximio que engañaba al abuelo Calisto. Los conflictos entre Demóstenes y Alejandro nos llevan al principio del pasaje «tú, que tienes más coraçón que Nembrot ni Alexandre» (I.41), puesto que el primero, el gran cazador y ejemplo de sobervia, es nieto de Cam, que suena y se escribía 'can', e impuso a su pueblo la adoración del fuego; y si «los enthymemas o argumentos de Demósthenes tenían olor de candil $»^{86}$ el debate entre Sempronio y Calisto, en el que se menciona precisamente el fuego (1.24-27), se desarrolla según el $M p$ a la luz de la vela. Lobera y Alii ${ }^{87}$ han observado el juego de palabras entre 'nieto' y 'can' e indican un testimonio de una posible fuente medieval en El caballero Cífar, amplío su cita:

E fallase por las estorias antiguas que Nimbros el valiente, visnieto de Noe, fue el primero rey del mundo, e llamanuanle los cristianos Nino. [...] E este linaje de Can, fijo de Noe, [...] que yogo con su muger en el arca, onde ouo vn fijo a que dixeron Cus, cuyo fijo fue este rey Nimbrot; e maldixo estonçe [Noé] Can en los bienes temporales. E otrosy dizen los judios que fue maldicho el can porque yogo con la cadiella en el arca. [...] E porende este rey Nimbrot que fue su nieto, fue malo contra Dios, e quiso semejar a la rays de su auuelo Can, onde veniera. ${ }^{88}$

84.- Cfr. Virginia Muñoz Llamosas, «Insultos e invectiva entre Demóstenes y Esquines», Minerva, 21 (2008), pp.33-49.

85.- Cfr. Virginia Muñoz Llamosa, art. cit.

86.- Plutarco, ob. cit., f. 104.

87.- Fernando de Rojas (y antiguo autor), La Celestina. Tragicomedia de Calisto y Melibea, Barcelona, Crítica, 2000, p. 383.

88.- Libro del Caballero Zifar, edición de Cristina González, Madrid, Cátedra, 1983, Epígrafe "Aqui cuenta de que linaje era este Cauallero de Dios, e de que tierra», pp. 95-96. 
Es el mismo chiste pero con el eje sexual invertido: (can / mujer) $\rightarrow$ (can / cadiella, 'perrita') $\rightarrow$ (Minerva / can). Se maldice a Cam y a su descendencia por su desvergüenza en el arca y por burlarse de la desnudez de Noé ebrio. La General Estoria dice de Cam que «era de menor entendimiento que los otros [hermanos]", elegante manera de afirmar que no era muy inteligente, y que «los moros vienen principalmente de Cam, que pobló África». ${ }^{89}$ La Sabiduría se ayunta con la desvergonzada Estulticia. Celestina comentada glosa la entrada "su desvergüenza» (I.47) en estos términos:

$Y$ porque son las mujeres ansi tan desvergonçadas se comparan a los perros que no ai animal mas desvergonçado. [...] dize [Nevizanes] que las mujeres tienen siete propiedades y son que en la iglesia parecen sanctas y en el ayuntamiento con ellas ángeles [...] y en casa parecen diablos y en las ventanas búhos y en las puertas picaças, y en las huertas cabras y en la cámara una hidiandez..$^{90}$

Son 'ángeles en la coyunda', es lo que también dice Sempronio en el chiste sobre Sodoma (I.36-38, falta esta hoja en el Mp.) «procuraron abominable uso con los ángeles no conocidos, y tú con el que confiessas ser Dios», y que repite Calisto en XI.24: «Parece que days a entender que los ángeles sepan hazer mal. Sí, que Melibea ángel dissimulado es que bive entre nosotros»; donde 'ángel disimulado' es parasinónimo de 'ángel no conocido'. Calisto sigue pensando en lo mismo; y la vieja barbuda les recuerda a los criados de éste que son "muy peynados» (XII.95), o sea afeminados. El sintagma «Minerva con el can» refleja pues la síntesis de dos chistes previos enlazados entre ellos:

\begin{tabular}{|c|c|c|c|}
\hline sintagma & «Minerva & con el & can» \\
\hline semema 1 & $\begin{array}{l}\text { Diosa } \\
\text { (mitología greco- } \\
\text { romana) }\end{array}$ & & animal \\
\hline $\begin{array}{l}\text { Semema 2: } \\
\text { homónimo }\end{array}$ & adúltera & & personaje bíblico \\
\hline $\begin{array}{l}\text { referencia sociolectal } \\
1\end{array}$ & $\begin{array}{l}\text { (Vidas paralelas) } \\
\text { chiste de Demós- } \\
\text { tenes }\end{array}$ & & $\begin{array}{l}\text { (Ant. Testamento) } \\
\text { chiste medieval } \\
\text { El caballero Cifar }\end{array}$ \\
\hline $\begin{array}{l}\text { referencia sociolectal } \\
2\end{array}$ & hijo del cuchillero & $\rightarrow$ & $\begin{array}{l}\text { el cuchillo del } \\
\text { abuelo Calisto }\end{array}$ \\
\hline
\end{tabular}

89.- Alfonso x, General Estoria, Primera parte, f. 20v y f. 22r, edición de Pedro Sánchez Prieto-Borja, Universidad de Alcalá de Henares, 2002.

90.- Ob. cit., pp. 34-37. 
El sintagma «lo de tu abuela con el ximio» se ha interpretado de diversas maneras: relaciones zoológicas documentadas en la literatura, ${ }^{91}$ raciales (converso, judío o negro), ${ }^{92}$ dichos populares,${ }^{93}$ errata por eximio, ${ }^{94}$ chiste, broma, pulla...95 El paso de Pasífae a la abuela de Calisto se comprende a la luz del mito de esta reina narrado por Alfonso $\mathrm{x}$ "que yerran las grandes senoras tan bien como las uassallas», ${ }^{96} \mathrm{y}$ si en lo referente a Minerva el punto de partida era Nembrot ahora lo es Alexandre: ${ }^{97}$

\section{Si Alexandro es kornudo, sépalo Dios y todo el mun- do. / Ke los males de los grandes señores no pueden ser enkubiertos. ${ }^{98}$}

Ahora bien, según el diagrama anterior hasta el momento sólo han aparecido los brutos animales, el toro y el perro, y queda pendiente los campestres o viles acemileros, esto es "el ximio", el último elemento de la serie. La Transición de 'can' a 'simio', metafóricamente de la desvergüenza a la lujuria, implica de alguna manera el paso semántico del 'maldecido

91.- Otis H. Green, "Lo de tu abuela con el ximio' (Celestina, auto I)», Hispanic Review, XXIv-1 (1956), pp. 1-12. También en "Celestina, Auto I: 'Minerua con el can'», Nueva Revista de Filología Hispánica, 7 (1953), pp. 470-74; Samuel G. Armistead and Joseph H. Silverman, "Algo más sobre 'Lo de tu abuela con el ximio' (La Celestina, I): Antonio de Torquemada y Lope de Vega", Papeles de Son Armadans, 205 (1973), pp. 11-18; Samuel G. Armistead, James T. Monroe, \& Joseph H. Silverman, «Was Calixto's Grandmother a Nymphomaniac Mamlūk Princess? (A Footnote on "Lo de tu abuela con el ximio» [La Celestina, Aucto 1]), eHumanista, 14 (2010), pp.1-23.

92.- Menéndez y Pelayo, Orígenes de la novela, Madrid, 1962, t. III, c. 39. Y también Alberto M. Forcadas, "Otra solución a 'lo de tu abuela con el ximio' (Aucto 1) de La Celestina», Romance Notes, 15.3 (1974), pp. 567-71, que propone como simio al judío Maimónides (p. 570).

93.- Marciales, ob. cit., I: 112-15 y II: 25.

94.- Erich von Richthofen, "Lo de la 'abuela con el ximio': otra expresión humanística y caballeresca (de LC)?», Cuadernos para Investigación de la Lit. Hispánica, 5 (1983), pp. 133-34; Miguel Garci-Gómez «El ximio [mono] de la abuela y el cuchillo del abuelo de Calisto: identificación", <http://mgarci.aas.duke.edu/celestina>. Garci-Gómez identifica como (e)ximio abuelo de Calisto al rey Enrique iv (1424-1474) de quien Alfonso de Palencia decía que tenía "gran semejanza con el mono».

95.- Lourdes Albuixech, «Insultos, pullas y vituperios en La Celestina», Celestinesca, 25 (2001), pp. 57-68.

96.- General Estoria, Segunda parte, ed. de Pedro Sánchez-Prieto Borja, Universidad de Alcalá, 2003, f. 300v.

97.- Recuérdese el cuentecillo medieval sobra las aventuras de Filis o Campaspe, amante de Alejandro, con Aristóteles: «¿E demás Aristótiles, uno de los letrados del mundo e sabidor, sostener ponerse freno en la boca e silla en el cuerpo, çinchado como bestia asnal, e ella, la su coamante, de suso, cavalgando, dándole con una correas en las ancas? [...] e de un tal gran sabio, sobre quantos fueron sabios, fazer dél bestia enfrenada andando a quatro pies, como bestia, una simple muger?» Corbacho, pp. 99-100. Cfr. Henri d'Andelli, Lai d'Aristote (s. XIII). Escena que Fernando Arrabal incluye en la mayoría de sus obras, sobre todo en su teatro pánico. Desde el punto de vista alegórico, este ejemplo es equivalente al de Minerva y el can: Sabiduría frente a Estulticia y Filosofía vencida por Lascivia.

98.- Correas, p. 276. También en Pedro Vallés (1549), r. 3376. 
Can', el siervo de siervos, ${ }^{99} \mathrm{y}$ de su linaje, ${ }^{100}$ al 'vil acemilero', de maldito a vil o campesino. Paso que se encuentra en el Libro de buen amor:

De la loçana fazes muy loca e muy bova; / fazes con tu grand fuego como faze la loba: / al más astroso lobo, al enatío, ajoba, / aquél da de la mano e de aquél se encoba. ${ }^{101}$

Se «encoba», queda preñada del "astroso", del «sucio, puerco, desaliñado, desharrapado y despreciable» (Autoridades) y vil. El vil acemilero es el simio en el sentido de que "al hombre disforme de cuerpo y de poco saber dezimos ser una azémila», y azemilón es "hombrazo tonto» (Covarrubias). Los refraneros ofrecen ejemplos de este tipo de relación metafórica:

- El ke no fue paxe, siempre güele a azemilero. / Aprovecha la buena krianza en la niñez (Correas, p. 102), (H. Núñez, 2875, f. 45v)

- Ni por kasa ni por viña, no tomes muxer ximia. / Entiende: rruin, que xima i tenga achakes i será para poko ${ }^{102}$ (Correas, p. 235), (H. Núñez, 5164, f. 82v).

- No presta la lexía en la kabeza del asno i kara de la ximia (Correas, p. 258).

99.- Lope García de Salazar, Istoria de las bienandanzas e fortunas, ed. de Ana María Marín Sánchez, Madrid, Corde, 2000, f. 97v.

100.- En el debate poético entre Gómez Manrique y Juan de Valladolid se cruzan acusaciones raciales y religiosas (judío, marrano, moro, hidalgo sin raza, cristiano viejo / nuevo...), en torno a la figura de Can: «En loaros syn mudança, / de raya jamás no salgo, / Manrrique; syn más tardança, / con la notable criança, / el vil se haze hidalgo. / Ya sabe vuestro valor / de toda exçelencia mora, [...] Y commo haze el mendigo / quando tiene alguna boga, / que da da d'ella a su amigo, / con un çelemín de trigo / los ençerré en la sinagoga, / y el linaje de Can / vino a mí con gran bolliçio / con dolor y con afán / [...] y pues soys tan desonestos / contra mí, que bien me rigo, / judíos...» (CXXVI). Las respuestas de Gómez Manrique son también muy duras: «y pues eres, mosé Juan, / no graçioso, mas agudo, / si valieres por truhán, / si no valdrás por cornudo.» (cXxII), "mas yo creo que su padre / sabe más del pregonar / lo que se suele perder, / y la puta de su madre / de los modos del andar, / qu'el hijo de conponer» (CXXVIII). «Pues saliendo de tal padre / tan elegante poeta, / alguna culpa secreta / deviera tener la madre» (cxxx). Gómez Manrique, Cancionero, pp. 329-348.

101.- Juan Ruiz, Libro de buen amor, ed. de Alberto Blecua, Madrid, Cátedra, 1992, p. 107, est. 402. El editor explica en la nota: "al más feo lobo, al vil, con él se junta». Alude a una tradición de historia natural muy difundida en la Edad media».

102.- Variantes en los refraneros de H. Núñez, Pedro Vallés. Louis Combet señala en nota: "El Comentador parece igualar el sentido de 'jimia' y 'maniaca'; de otro modo lo entiende Mal Lara: 'en los casamientos, no se mire solamente la hazienda, ni diga uno casa y viña, si la muger es fea, de mala condición y para poco, según es la ximia o mona...' (t. II, 126). También Oudin: 'Ni pour maison, ni pour vigne, ne prends femme singesse. Laide et contrefaite comme un marmot' (Refranes, p. 200).» Cfr. Gonzalo Correas, Vocabulario de refranes y frases proverbiales, edición de Louis Combet, Burdeos, 1967. 
- Servir komo moro, medrar komo mono (Correas, p. 275).

- Kien por el mundo kiere andar salvo [h]a menester oxos de halkón i orejas de asno, kara de ximio, boka de puerko, espaldas de kamello i piernas de ziervo. / La boka de puerko para comer de todo, i estómago para engullir i soportar dichos i hechos kon espaldas de kamello: lo demás es klaro (Correas, p. 408).

- Tal piensa que adora un ángel, y viene a adorar un ximio (Quijote, II, II).

Alfonso Martínez de Toledo escribe «que quando la vieja está bien arreada e bien pelada e llepada paresçe mona desosada!», y «las mugeres quieren saber tocar e las monicas afeitar». ${ }^{103}$ Espinosa recoge la paremias "Es un jimio", $y$ "Sabe más rruyndades que una mona». ${ }^{104}$ La confirm ción de que el 'ximio' es el 'vil o campestre acemilero' se encuentra en el Tratado de Centurio en donde Sosia recibe este tratamiento:

[[ELICIA.- (Aparte, escondida.) (jTiénente, don handrajoso! ¡No es más menester! ;Maldito sea el que en manos de tal azemilero se confía! ; Qué desgoznarse haze el badajo!)]] (XVIIT.31)

[[(AREÚSA.-) jAllá yrás, azemilero! ;Muy ufano vas, por tu vida! (34) Pues, toma para tu ojo, vellaco] ${ }^{105}$ (XVIIT.33-34).

El «simple rascacaballos», de pocas luces, según su compañero Tristán (XIvT.23), lo confirma él mismo

[[Pero yo te juro por el peligroso camino en que vamos, hermano, y assi goze de mi, que estuve dos o tres vezes por me arremeter a ella, sino que me empachava la vergüença de verla tan hermosa y arreada y a mi con una capa vieja ratonada. Echava de si en bulliendo un olor de almizque; yo hedía al estiércol que llevava dentro de los çapatos]] (XIXT.3).

Sosia se nos presenta como un acemilero tonto, sucio, desharrapado, mal oliente y que piensa hacer con la moza Areúsa lo mismo que el 'ximio' con la abuela de Calisto. O al revés, la abuela hizo lo que «muchas», cometer adulterio con un 'vil acemilero'. Por otra parte, Sempronio, el autor de la frase y el que estaba precisamente 'curando los caballos' en los inicios de la obra, está asociado en la literatura medieval con el ladrón de acémilas:

103.- Corbacho, ob. cit., pp. 181-182 y p. 263.

104.- Francisco de Espinosa, Refranero (1527-1547), edición de Eleanor S. O'kane, Madrid, Anejos del Boletin de la Real Academia Española, 1968, pp. 134 y 212 (J 297v y J 204v).

105.- Con el doble corchete en cursiva indico las adiciones segundas o impresas en CL-21. 
El confessor precioso, de la voluntad larga, / avié una acémila, bestia era de carga, Turibio e Simpronio vidiéronla amarga, / por so mal la modraron del pasto de la Varga. Teniéla el buen omne non para cavalgar, / mas por a los mezquinos leña acarrear; ovieron con cobdicia los torpes a cegar, / fueron en ora mala l'acémila furtar. ${ }^{106}$ (est. 271-272)

El Tratado de Centurio (XIvT.29-34) recuerda a «don Ximio, ordinario alcalde de Bugía», ${ }^{107}$ a ese "hombre de baxo suelo" y que "hizo alcalde mengua de hombres buenos» (31), 'compañero de los sirvientes de Calisto y de sus antepasados'.

Estas "porradas», que no son "hablillas», ${ }^{108}$ nos llevan al tercer sintagma "el cuchillo de tu abuelo Calisto" $(M p)$. Se ha interpretado "cuchillo» como 'cuclillo', ${ }^{109}$ cornudo (el mango o cabo es de cuerno), ${ }^{110}$ como símbolo fálico y erótico (cuchillo / vaina), ${ }^{111}$ como intercambio de favores según la edad de la dama, de joven los recibe y de vieja los regala (cuento oriental), ${ }^{112}$ como parodia de la venganza de honor... ${ }^{113}$ Ese "cuchillo» es «testigo" directo del adulterio de la abuela con el vil acemilero y tiene muy poco de erótico, pues el abuelo no forma parte de la serie de los fornicios sino de la serie de los cornudos. En la literatura medieval es frecuente el uso del sintagma 'cuchillo de...»: saña, crueza, dolor, venganza, espíritu, argumentación, justicia; incluso el 'rey es cuchillo de los traidores'. Gómez Manrique dice de su tío el marqués de Santillana: «Vos sois

106.- Gonzalo de Berceo, Vida de San Millán de la Cogolla, ed. de Brian Dutton, Madrid, Espasa-Calpe, 1992.

107.- Libro de Buen Amor, est. 325.

108.- «a los que este libro leyeren que no tomen enojo [...] por quanto para viçios e virtudes farto bastan enxiemplos e prácticas, aunque parescan consejuelas de viejas, pastrañas o romançes; e algunos entendidos reputarlo han a fablillas, e que non era libro para en plaça». Corbacho, ob. cit., p. 204. Recuérdese que los Fueros castigaban con fuertes multas este tipo de denuestos.

109.- Marciales, siguiendo un comentario de Von Barth, ob. cit., II, p. 25. Terminado este artículo, ha aparecido el trabajo de Luis Gómez Canseco, que propone también la lectura «cuclillo»: "El cuchillo de tu abuelo. En torno a la edición de un lugar oscuro en el acto I de LC», Celestinesca, 39 (2015), pp. 27-38.

110.- Lobera y Alii, ob. cit., p. 383. Quevedo ofrece un buen ejemplo: "Que pretenda el maridillo / De puro valiente y bravo, / Ser en una escuadra cabo, / Siendo cabo de cuchillo». Ed. cit., p. 271.

111.- Garci-Gómez, art. cit. En red.

112.- Henry N. Bershas, "Testigo es el cuchillo de tu abuelo (Celestina I)», Celestinesca, 2-1 (1978), pp.7-11.

113.- Françoise Vigier, «Quelques reflexions sur le lignage, la parenté et la famille dans la 'celestinesque'», Autour des parentés en Espagne aux xviè et xviiè siècles. Histoire, mythe et littérature, ed. de A. Redondo, París, La Sorbonne, 1987, pp. 157-174. 
fuerte muro de los aflegidos, / agudo cochillo de los malfechores», ${ }^{114}$ en tanto que atributo de la virtud cardinal de la justicia. También «la casta Lucrecia / con esse cuchillo que se desculpó» (Mena, LXIII). El arcipreste de Talavera avisa claramente al que ama "pues si es razón de querer tal amor que dones promete e después tú ser la pieça, e él cuchillo». ${ }^{115}$ Por tanto, el "cuchillo» es, en este caso, "testigo", juez, verdugo, ${ }^{116}$ y calderoniano 'médico de su honra'. ${ }^{117}$ No es casual que el abuelo cuchillero, como el del chiste de Minerva, se llame también Calisto $(M p)$, y esta es precisamente la vía que sigue el Tratado de Centurio en la saga de los nombres del rufián acuchillado y del campestre acemilero:

[[Por ella [la espada] le dieron Centurio por nombre a mi abuelo, y Centurio se llamó mi padre, y Centurio me llamo yo]] (xviIIIT.15).

[ [si por hombre de linaje, ya sabrá que te llaman Sosia, y a tu padre llamaron Sosia, nascido y criado en una aldea, quebrando terrones con un arado, para lo qual eres tú más dispuesto que para enamorado]] (XIXT.6).

Parodia picaresca, pero es evidente que el Tratado se inspira en el $M p,{ }^{118}$ el "campestre azemilero» recuerda al acemilero «quebrando terrones». Centurio tiene la cara acuchillada (xvT.4 y xvIITB.18) al igual que la vieja Trotaconventos (I.105, Iv.18 y xiII.20), y es de suponer que la abuela de Calisto también la tenga, pues según Sempronio es tan comadre como la abuela de Elicia, quien mostrara el oficio a Celestina (vIr.109); como Claudina, madre de Pármeno, "prima del oficio» (vir.35) y "tan puta vieja» (I.137) como la alcahueta, que padeció «recios tormentos» (vir.49) y fue

114.- Marqués de Santillana, Comedieta de Ponza, sonetos, serranillas y otras obras, ed. de. R. Rohland de Langbehn; Estudio preliminar de V. Beltrán, Barcelona, Crítica, 1997, p. 3.

115.- Alfonso Martínez de Toledo, Arcipreste de Talavera o Corbacho, ed. de Michael Gerli, Madrid, Cátedra, 1981, cap. XIII, p. 90.

116.- «E devedes saber que el juizio es cuchillo, según dize Sant Gregorio, que el juizio es pena e correpçión postremera e acabamiento e fin de todas las obras; que qualquier que agora non llorare sus peccados e non fiziere en este mundo penitençia dellos, estonçe non podrá escapar deste juizio que es dicho cuchiello.» Anónimo (¿1400 - 1500?), Un sermonario castellano medieval, ed. de Manuel Ambrosio Sánchez, Salamanca, Universidad de Salamanca, 1999, f. 106. Quevedo lo aplica a los médicos: «Yacen de un home en esta piedra dura / El cuerpo yermo y las cenizas frías: / Médico fue, cuchillo de natura, / causa de todas las riquezas mías». Ed. cit., p. 54.

117.- «Mas los maridos que sabiendo que sus mugeres les cometen adulterio lo vengan matando a ellos y a ellas ora por su propia auctoridad ora por justiçia no se pueden con razón llamar cornudos porque ellos no lo consienten antes lo castigan y vengan. Y así quando ellos así lo hazen suelen dezir, 'cuernos fuera'.» Sebastián de Horozco, El libro de los Proverbios glosados, ed. de Jack Weiner, Kassel, Edition Reichenberger, 1994, t. I, pp. 522-523.

118.- A veces tengo la impresión de que el Tratado de Centurio se escribió al mismo tiempo que la prolongación de CL-12; en todo caso, antes de que se publicaran las Comedias. 
exhibida en lo alto de una escalera con un 'rocadero pintado en la cabeza' (VII.43) a imagen y semejanza del burlado Virgilio colgado en un cesto (vil.45); esto último según el continuador; ${ }^{119}$ todo ello en el marco de la comedia terenciana donde se reflejan las tres generaciones de comadres

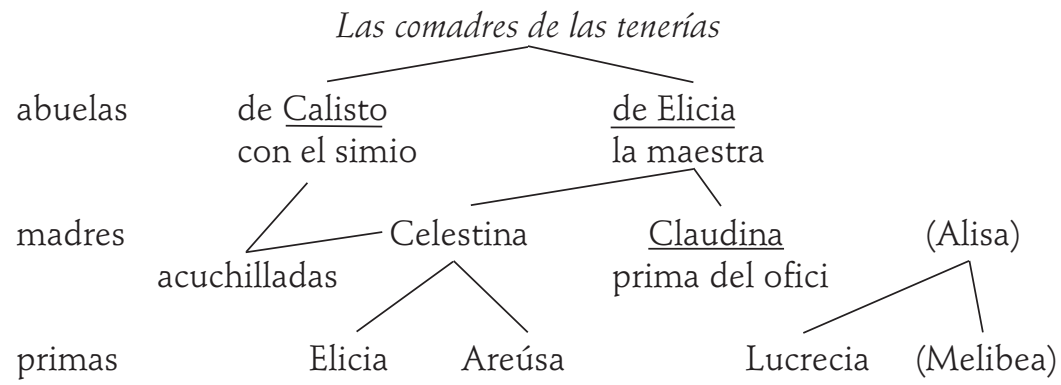

Según Calisto nieto, Sempronio es necio y dice necedades. Sin embargo, en las versiones impresas de CL se observa un lavado textual, una clara censura, puesto que se disimula el nombre del abuelo y la negación de necedad de Sempronio ("no se s'y so neçio n[...]»); pero si Calisto se 'escuece' es porque algo hay de cierto en las palabras del criado. Esta atenuación censora es más evidente en lo que parece ser una adición primera en las ediciones impresas (I.44-46): comadres de las tenerías», en Ma I. Sancho, L. Ruiz y F. Gutiérrez (editores), Estudios sobre lengua, Literatura y Mujer, Jaén Universidad de Jaén, 2006, pp. 63-130. 


$$
\text { Mp-a, f. } 96 \text { r }
$$

cons'ejate con seneca \& veras enque las tiene y escuch( )a all aristotil mjra / al bernaldo gentiles' judios xpistianos moros' todos enesta [*con]cordia estan ${ }^{119-1}$ qujen te contaria sus mentiras s'u[ ${ }^{*} \mathrm{~s}$ cam] bios sus trafagos' s'us hurtos su ljviandad $s\left[{ }^{*} \mathrm{us}\right]$ lagrimjllas s'us' altercaçiones' sus' os'adias que [...] lo que piens'an osan s'y pueden.

$+\left[{ }^{*}\right.$ pero lo dicho y lo que dellas dixere no te] [...]
CL I.44-46

(44) Conséjate con Séneca y verás en que las tiene. Escucha al Aristóteles, mira a Bernardo. Gentiles, judíos, cristianos y moros, todos en esta concordia están. [Pero lo dicho y lo que dellas dixere, no te ; contezca error de tomarlo en común (45) que muchas ovo y ay santas, virtuosas, y notables, cuya resplandeciente corona quita el general vituperio . Pero destas otras,] ¿quién te contaría sus mentiras, sus tráfagos, sus cambios, su liviandad, sus lagrimillas, sus alteraciones, sus osadías? Que todo lo que piensan, osan sin deliberar: (46)

Es tal la extensión del texto carente en la plana del $M p$-a que no puede tratarse de un olvido del copista, ${ }^{120}$ y además esas líneas impresas desbaratan y anulan el efecto del discurso misógino y su precisa función terapéutica para sanar el mal de amores de Calisto. Sin olvidar que el $M p$-a no presenta los vicios de las mujeres en el mismo orden (cambios-tráfagos / tráfagos-cambios), añade el vicio de latrocinio ("sus hurtos»), cambia sus «alteraciones» (estados de ánimo) por "altercaciones» (disputa entre dos o más personas), y «sin deliberar» por "s'y pueden», excluyendo de esta guisa la posibilidad de que las mujeres tengan el don de la reflexión

En CL-12 no hay comadres sin compadres; con lo cual el abuelo Calisto tiene los mismos atributos ${ }^{121}$ que el marido de Celestina y el bueno de Alberto, padre de Pármeno y esposo de Claudina, y por supuesto el propio Sempronio, el Amigo ausente de Areúsa, y los Juanes con los que

119-1.- "Cruz en el texto que remite a otra en la margen que a su vez remite a otra en la margen inferior medio cortada por el encuadernador». Faulhaber, art. cit., p. 21.

120.- Michel García no piensa que sea una omisión: «se parece más a un inciso posterior encargado de atenuar la misoginia de las elucubraciones de Sempronio que a una omisión del copista». En «Apostillas a "Consideraciones sobre Celestina de Palacio», p. 147.

121.- Aunque según Sebastián de Horozco: «Mas los maridos que sabiendo que sus mugeres les cometen adulterio lo vengan matando a ellos y a ellas ora por su propia auctoridad ora por justiçia no se pueden con razón llamar cornudos porque ellos no lo consienten antes lo castigan y vengan». El libro de los proverbios glosados, edición de Jack Weiner, Cassel, Reichenberger, 1994, t. II, p. 522-23. 
topa Celestina justo antes de llegar a casa de Melibea: ${ }^{122}$ "quatro hombres que he topado, a los tres llaman Juanes, y los dos son cornudos» (Iv.12). Es decir:

$$
\text { Cp-b, f. 99v. }
$$

\section{P. que encomendador su}

marido de huevos' asados'. que quieres' mas', si no que si una piedra topa con otra, luego suena puta vieja . C . y tu commo la conoçes'.

$$
\text { CL I.92 }
$$

La primera frase ha dado lugar a múltiples estudios críticos sobre la forma léxica y el contenido semántico. Estando generalmente de acuerdo sobre la significación de "cornudo", el debate filológico se plantea en torno a: ¿comedor, comendador o encomendador?, ${ }^{223}$ ¿Costumbres judías en los velatorios, ${ }^{124}$ reconstituyente sexual, ${ }^{125}$ afrodisíaco, ${ }^{126}$ interpretación erótico-genital... ${ }^{127} ?^{128}$ Empecemos por el fondo antes de abordar la forma. En $L C$ no hay funerales, ni cristianos ni judíos ni moros; y, por otro lado, el marido de la partera, al igual que el abuelo Calisto, no es en la frase sujeto de relaciones sexuales sino la 'víctima' del engaño, del adulterio, fuere consentido o no lo fuere, y en consecuencia no le son de aplicación ni los afrodisíacos, ni los reconstituyentes ni la explicación erótico-genital; los cuales pueden ser usados tanto por aquellos maridos engañados

122.- La frase siguiente se refiere a «achaque de amores» lo que da pie a pensar en una Melibea casada con un Juan cornudo. Cfr. Cantalapiedra (2000, t. 2: pp.386-87; t. 3: 1291-1292).

123.- Joseph E. Gillet, "Comedor de huevos (?). Celestina, auto I», Hispanic Review, 24 (1956), pp.144-147; Enrique J. Fernández-Rivera, "'Huevos asados’: Nota marginal», Celestinesca, 17-1 (1993), pp. 57-60; Juan M. Escudero, "La expresión 'comedor / encomendador de huevos asados en La Celestina», Rivista di Filología e letterature Ispaniche, I (1998), pp. 197-201.

124.- Peter B. Goldman, "A new interpretation of «comedor de huevos asados. (La Celestina, aucto I", Romanische Forschangen, LXXVII (1965), pp. 363-367.

125.- Cfr. Joseph E. Gillet, art. cit., p. 145.

126.- Miguel Garci-Gómez, "Huevos asados': afrodisíaco para el marido de Celestina», Celestinesca, 5 (1981), pp. 23-34. También en red: <http://mgarci.aas.duke.edu/celestina/CELESTINA/ENSA/HUEVOS.HTM>; Kish Kathleen y Ursula Ritzenhoff, "On translating 'huevos asados': clues from Christof Wirsung», Celestinesca, 2 (1981), pp. 19-31; Louise O. Vasvari Fainberg: « $\bigcirc$, qué comedor de huevos assados era su marido!: Farther Glosses on the vocaburlario of Celestina, IV», en José Manuel Hidalgo (ed.) 'La pluma es la lengua del alma'. Ensayos en honor de E. Michael Gerli, Neward, Delaware, Juan de la Cuesta, 2011, pp. 367-386.

127. - Marciales, II.35, nota al pasaje I.92: huevo = miembro viril / pene erecto; comegüevos, cornudo aprovechado...

128.- Cantalapiedra, (2000), III, pp. 1075-177. Para el último estado de la cuestión, véase: José Antonio Torregrosa Díaz, "Tragicomedia de Calisto y Melibea». Anotaciones Críticas y Textuales y Versión Modernizada. Tesis doctoral, Universidad de Murcia, 2015, pp. 130-132. 
como por los que no lo son. La explicación debe ser de otra índole. El cuchillo del abuelo Calisto y la «señaleja de la cara» de Celestina (IV.42) indican que el marido engañado puede reaccionar con ira y sufrir comezón, en sentido figurado ${ }^{129}$ En la medicina medieval, el colérico, furioso, es de complexión seca y caliente y su naturaleza es el fuego; o sea, es de sangre caliente. El escocimiento se definía en estos términos: "Prurigo, que es comezón, es así llamada de pruriendo o de perurendo et ardendo, esto es, de 'comiendo' o de 'quemando e ardiendo». ${ }^{130}$ El Diccionario de Autoridades establece la misma relación entre picor y hervor: "Comezón. s. m. Picazón en alguna parte del cuerpo, que desazona y molesta mucho, por ser vehemente: $y$ a veces se padece en todo el cuerpo por algún hervor de la sangre u otra causa». Y eso es lo que dice Melibea a Celestina: "que me comen este coraçón serpientes dentro de mi cuerpo» (x.8). CL ofrece en varios lugares la figura 'hervir la sangre' asociada con la imagen del iracundo:

- cuánto más estas que hierven sin fuego (III.28, Celestina sobre Melibea).

- que no me ha dexado gota de sangre en el cuerpo! (IV. 60, Melibea sobre Celestina).

- la sangre nueva poco calor ha menester para hervir (IV. 68, Celestina a Melibea).

- la sangre me hierve en el cuerpo (XII.71, Sempronio sobre la fingida afrenta)

[[Esta herida es la que siento, agora que se ha resfriado, agora que está elada la sangre que ayer hervía]] (XIVT. 26, Calisto, tras la escena del huerto).

Los huevos asados se utilizaban en los preparados farmacéuticos para curar este tipo de enfermedades:

- Para el que llaman vsagro que es comezon [...] Para este vsagro o sarna menuda yemas de hueuos asados duros $\&$ desatados con azeite de eneldo \& vnten \& poluorizen ençima con alheña o aluayalde II Las algarrouas son buenas para Restreñir Esso mesmo yemas de hueuos asados \&

129.- En el último tercio del siglo xv ya circulaba el refrán "Quien cornudo es y se calla, comezón trae en la saya». Diego García de Castro, Seniloquium, r. 425, p. 316. Núñez ofrece la variante: "Quien es cornudo y calla, en el corazón trae un ascua». H. Núñez, Refranes o proverbios en romance, f. 112 r, p. 219.

130.- Anónimo, Las Etimologías romanceadas de San Isidoro, ed. de Joaquín González Cuenca, Universidad de Salamanca-CSIC-Institución Fray Bernardino de Sahagún-Diputación provincial de León, Salamanca, 1983, p. 254. CORDE. 
bien duras \& eso mesmo dizen cozjdos en vinagre con su casta $\&$ despues comer aquellas yemas duras. ${ }^{131}$

- Reçebta de melezina que presta a las fendeduras \& a la comezon: toma mastic [...], buelvelo con el ollio rosado \& buelve con el yema de huevo asado \& unta con el logar. Il Reçebta de la mellezina que presta cochura del sieso \& del llater \& el dollor grande: toma de fojas de velleno \& fojas de verdolagas \& cal remojada en agua fria \& yema de huevo asado. II[Tiña] \& curala con dos yemas de huevos asados fasta que sea unguento \& unta con ello la cabeça del moço o quier que fuere la tina. II [Las fendeduras] \& el que non oviere postema agudez presta dende que tomes yema de huevo asado. II Reçebta de comer para quel non finca vianda en el estomago por la grant dollor: coma yema de huevo asado \& de la miel, dos cuchares. ${ }^{132}$

- para comezon e bermejor toma vn huevo asado. ${ }^{133}$

- \& sy vieres otrosy que la materia fuere colerica \& ençendida \& el enfermo fuere fuerte \& rrezjo rresfriemos los estentinos antes que se quemen conel ençendimjento dela colera [...] Toma rramos de verdolagas con agua rrosada \& el caldo del trigo cocho \& colado quatro libras \& delos hueuos asados. ${ }^{134}$

-Para dolor de la teta de muger. Toma la manteca cruda de las uacas \& las macanas podridas. \& las yemas de los hueuos assados que sean bllandos \& maialo todo en vno bien fata que sea encorporado con leche de muger Et ponergelo sobre la teta asi como emplasto a menudo asi que quanto lo vno fuere seco. ponerle otro \& tollerle a el dolor \& amansarielo ha. ${ }^{135}$

131.- Alfonso Chirino (a 1429), Menor daño de la medicina, mss. del Escorial, b.rv.34, ed. de Enrica J. Ardemagni, Ruth M. Richards, Michael R. Salomon, Madison, Hispanic Seminary of Medieval Studies, 1987, f. 75. CORDE.

132.- Anónimo (a 1500), Tratado de patología, ed. de María Teresa Herrera, Universidad de Salamanca, 1997. CORDE.

133.- Anónimo (c 1471), Traducción del Libro de recetas de Gilberto, Madrid, Biblioteca Palacio 3063, ed. de María Teresa Herrera y María Estela González de Fauve, Madison, Hispanic Seminary of Medieval Studies, 1997.

134.- Anónimo (1450-1500), Tratado de las fiebres de Ischaq Israeli, mss. Bibl. Escorial M.I.28, ed. de Ruth M. Richards, Madison, Hispanic Seminary of Medieval Studies, 1995. CORDE.

135.- Anónimo, Tesoro de la medicina (Tesoro de los remedios) (1431), Sevilla, Colombina 5117, ed. de María Teresa Herrera; María Estela González de Fauve, Madison, Hispanic Seminary of Medieval Studies, 1997, f. 25r. CORDE. 
- Remedio para el fluxo de sangre. Tomá una quarta de ençienso, y otra de almástiga, y una balosta y tres nuezes moxcadas y media dozena de clabos. Moled todas estas cosas y passadlas por çedaço. Y la muger que tubiere esta enfermedad, tome dos huevos asados, que estén muy blandos, y vazíeles la clara, y hínchalos destos polvos y bébalos. Haga esto nueve mañanas y sanará de la enfermedad. ${ }^{136}$

Según estas prácticas médicas los huevos asados restriñen el flujo sanguíneo, constriñen, contienen, cicatrizan la herida, amansan y calman la comezón y al iracundo. Y en sentido traslaticio hacen del cornudo un esposo paciente. El refrán de los huevos asados es en cierto modo paralelo de las paremias, aún en uso: "Kien se pika, axos à komido. Tú ke te kemas, axos as komido. Tú ke te pikas, axos as komido», ${ }^{137}$ y que pueden entenderse a la luz del siguiente texto medieval:

E quando una persona colerica usa mucho del ajo el lo enflama \& le escaliente el cuerpo \& lo seca $\&$ lo dispone a ser lazaro \& a frenesia \& aun turva la vista. ${ }^{138}$

Alfonso Martínez de Toledo brinda un ejemplo literario del engarce semántico entre el colérico, las cuchilladas y los huevos:

¿Paresçe vos esto bien que Fulana o Fulano me ha desonrado en plaça? ¿E cómo? Bien a su voluntad llamándome puta amigada. Díxome puta casada [...]. ¿quién vos firi por la cara?» o "Quién vos mató?» [...] ¡Ay triste de mí! ¡Daca huevos; daca estopa; daca vino para estopada! Juanilla, ve al çurujano; dile que venga. ¡Corre aína, puta, fij de puta! Marica, daca una camisa delgada, que se le va toda la sangre. [...] Veele que tiene la cara atravesada. ${ }^{139}$

De todos modos, el sentido exacto de la relación entre el cornudo y lo huevos asados sigue siendo tan oscuro como cuando Juan de Arce de Otálara escribía hacia 1550:

136.- Anónimo (a 1525), Manual de mugeres en el qual se contienen muchas y diversas reçeutas muy buenas, ed. de Alicia Martínez Crespo, Salamanca, Ediciones de la Universidad de Salamanca, 1995, p. 44. CORDE.

137.- Correas, pp. 508, 723; H. Núñez, 7984, f. 127r.

138.- Fray Vicente de Burgos, Traducción de El Libro de Propietatibus Rerum de Bartolomé Anglicus (1494), Del ajo, cap. IX, ed. de Ma Teresa Herrera; Ma Nieves Sánchez, Salamanca, Universidad de Salamanca, 1999. CORDE.

139.- Ob. cit., cap. VIII, "Del colórico, qué dispusición tiene para amar e ser amado». pp. 218- 219. 
Palatino.- Aún no me sabréis decir ¿por qué encomiendan los huevos a los cornudos? Cuando los ponen a asar? ¿Para que no salten? [...]

Pinciano.- [...] a mi parescer debe ser la causa porque los cornudos son pacientes y sufren mucho y nunca saltan, aunque toque el fuego de Vulcano, o porque sus mujeres los regalan con ellos para tenerlos sanos y recios para sus necesidades.

Palatino.- Buenas razones son esas, para no saber el original. Yo tampoco lo sé, aunque he preguntado a muchas personas. ${ }^{140}$

Las formas 'comedor, comendador, encomendador' (comendar en sentido de encomendar se usó hasta el siglo XVI $)^{141}$ son variantes usuales de este refrán; aunque es posible que la primera forma diera lugar a las siguientes, por lo comentado sobre las recetas y por otro refrán similar, que recuerda a Centurio, al cuchillo del abuelo y a los rostros acuchillados:

Komía Tragamalla guevos kochos kon zernada. ${ }^{142}$ || Tragamalla. Apodo a un valentón, komilón i engullidor (Correas, 432 y 739, H. Núñez, 1708, f. 27v).

Precisamente Centurio, el soldado fanfarrón, hace crujir la malla (XviIITB.8), la destroza (xviIT.14) y tiene por colchón «un rimero de malla rota» (XVIIIT.7), aunque carece de los medios para ofrecer una simple colación a las mozas Areúsa y Elicia (XviIIT.7). Correas recoge una paremia que asocia los huevos con las ganancias: "No Kome guevos por aguelos. / Kiere dezir: sino por la hazienda ke kada uno tiene al presente». ${ }^{143}$ Pedro Vallés (1549) emplea el doblete "comedor o comendador»; ${ }^{144}$ pero años después se sigue empleando el primer término en manuales de enseñanza de la lengua española:

Francisco.- ¿Toda la vida has de comer tú cabrón?

140.- Coloquios de Palatino y Pinciano, ed. de J. L. Ocasar Ariza, Madrid, Turner-Biblioteca Castro (1995), pp. 126-127. Texto citado por Juan M. Escudero (1998), y por José Antonio Torregrosa Díaz (2015).

141.- «Encomendador. s. m. Lo mismo que Comendador» (Autoridades). Patrizia Botta, El texto en movimiento, coloca «encomendador» entre las «lecciones mejores», p. 148.

142.- «Suelen con ella cargar o enbarrar los pechos y ancas de las bestias que se han refriado» (Covarrubias, p. 409). O sea, cataplasma para las acémilas.

La Lozana llama Tragamallas a Rampín y le encantaba comer «cocho», fornicar: «iCuánto había que no comía cocho!», "y sabido por Diomedes a qué sabía su señora [La Lozana], si era concho o veramente asado». Francisco Delicado, La Lozana Andaluza, ed. de Claude Allaigre, Madrid, Cátedra, 1985, p. 282, 232 y 183.

143.- Correas, p. 257.

144.- Pedro Vallés, Libro de refranes, 1549, p. 39. 
GUZMÁn.- ¡Oh, Dios te bendiga la bella alimaña!

Francisco.- ¡Oh, Dios te despache deste mundo para el otro!

GuZMán.- Dícenme que es vuestra merced gran comedor de huevos asados.

Francisco.- También me han dicho a mí que vuestra merced come muy bien bacalao. ${ }^{145}$

Donde «bacalao» alude a las prostitutas baratas. La forma 'comendador' es de uso en el siglo Xv:

A ti, fray Cuco Mosquete, / de cuernos comendador, / ¿qué es tu ganancia mayor, / ser cornudo o alcagüete? ${ }^{146}$

Esta es la forma, comandator, que emplea Ordóñez en su traducción al italiano (1506), y Sedeño (1540) en su versión en verso, comendador. Aunque la forma más corriente parece ser la tercera:

Enkomendador de guevos asados. / Es dezir, ke uno es kornudo. Tiene el vulgo hablilla i opinión, en burlas no en veras, ke enkomendando los guevos ke se ponen a asar a un kornudo, no se kebrarán (Correas, p. 138).

Enkomendador de guevos asados. / Dízese de uno por mui kornudo; porke tiene armas kon ke los defender i guardar. "Armadura» se dize la kornamenta del buei» (Correas, p. 621)

El autor de Celestina Comentada, en una nota marginal corrige comedor por la segunda forma: "Alius a de dezir: 'O que conmendador de huevos' para dar a entender que era cornudo» (g. 116a, p. 69). No obstante, la evolución en el uso de esas formas implica un cambio de sentido semántico, pasando de 'paciente sufridor', el comedor, a tener el usufructo de los beneficios - "las rentas que tienen, por consistir en diezmos y primicias, se llaman Encomiendas» (Aut.)—, el encomendador; esto es, el encomendador / comendador es el 'alcahuete o padre de la putería', el que tiene encomendadas las mozas. La lectura del $M p$ se aproxima un poco más a la idea del abuelo Centurio, que «fue rufián de cient mugeres (XviIT.16), y da a entender, desde el punto de vista de Pármeno, que el marido de la Al-

145.- Anónimo (1599), Diálogos de John Minsheu, ed. de Miguel Marañón Ripoll y Lola Montero Reguera, Alcalá de Henares, Centro Virtual Cervantes, 2004. Siete de estos diálogos, incluido este pasaje, los toma prestados Juan de Luna, con la intención de 'corregir sus más de quinientas faltas', en su Diálogos familiares en lengua española, París (1619), p. 400, y en Bruselas, chez Hubert Antoine (1625). Lo edita asimismo José María Sbarbi, Impr. Gómez Fuentenebro, Madrid, (1874) p. 250.

146.- Anónimo (1465-1466), Coplas del Provincial, ed. de Julio Rodríguez Puértolas, Madrid, Castalia, 1989, p. 242. 
cahueta sigue vivo, mientras que el verbo en pretérito de las $C L$ impresas, «era», implica su fallecimiento, tan difunto como su compadre Alberto (I.139), lo que confirma ella misma en Iv.49-51:

(49) Que con mi pobreza jamás me faltó, a Dios gracias, una blanca para pan y un quarto para vino, después que embiudé, $[\ldots][[\ldots]]$ (51) Assí, que 'donde no ay varón todo bien fallesce'.

$M p-b$ omite una parte de las preguntas de Calisto «Y tú, ¿cómo [lo sabes y] la conosces?» Es lo mismo que preguntó a Sempronio cuando este le ponía en guardia contra los engaños de las mujeres: "y tu que s'abes' qujen te mos'tro es'to» (Mp-a, f. 97r) / "Y tú ¿qué sabes? ¿Quién te mostró esto?» (I.54). La respuesta en los dos casos es la misma, «ellas» en general y 'ella' en particular; de este modo, la omisión del cuidadoso copista de $M p-b$ se subsana con el descuidado texto de $M p$ - $a$.

\section{Bibliografía citada}

AlbuiXeCH, Lourdes, «Insultos, pullas y vituperios en La Celestina», Celestinesca, 25 (2001), pp. 57-68.

Amasuno, Marcelino v., Sobre la Aegritudo Amoris y otras cuestiones fisiátricas en 'La Celestina', Madrid, CSIC, Anejos de la Revista de Filología Española, 2005.

ANÓNIMO (1450-1500), Tratado de las fiebres de Ischaq Israeli, Bibl. Escorial M.r.28, ed. de Ruth M. Richards, Madison, Hispanic Seminary of Medieval Studies, 1995.

Anónimo (¿1465 - 1466?), Coplas del Provincial, ed. de Julio Rodríguez Puértolas, Madrid, Castalia, 1989.

Anónimo (1599), Diálogos de John Minsheu, ed. de Miguel Marañón Ripoll y Lola Montero Reguera, Alcalá de Henares, Centro Virtual Cervantes 2004. Anónimo (c 1525), Manual de mugeres en el qual se contienen muchas y diversas reçeutas muy buenas, ed. de Alicia Martínez Crespo, Salamanca, Ediciones de la Universidad de Salamanca, 1995.

Anónimo (c 1471), Traducción del Libro de recetas de Gilberto, Biblioteca Palacio 3063, ed. de María Teresa Herrera y María Estela González de Fauve, Madison, Hispanic Seminary of Medieval Studies, 1997.

Anónimo / Fernando de Rojas, TragiComedia de Calisto y Melibea, edición crítica de Fernando Cantalapiedra Erostarbe, Kassel, Edition Reichenberger, 2000, Tres tomos.

Anónimo, Libro del Caballero Zifar, edición de Cristina González, Madrid, Cátedra, 1983. 
Anónimo, Adagios, Proverbios o sentencias varias (en romance y en latín), Ms., s. XVI, entre 1501 y 1600. Signatura Mss / 4502. Biblioteca Nacional de Madrid.

Anónimo, Celestina Comentada, edición de Louise Fothergill-Payne, Enrique Fernández Rivera y Peter Fothergill-Payne, Salamanca, Universidad de Salamanca, 2002.

Anónimo, Segunda parte del Romancero general y Flor de diversa poesía recopilados por Miguel de Madrigal (1605), ed. de Joaquín de Entrambasaguas, Madrid, CSIC, 1948.

Anónimo, Un sermonario castellano medieval, ed. de Manuel Ambrosio Sánchez, Salamanca, Universidad de Salamanca,1999.

Anónimo, Coplas de Mingo Revulgo glosadas por Fernando del Pulgar, Salamanca, Juan de Porras ¿1498?

Anónimo (a 1500), Tratado de patología, ed. de María Teresa Herrera, Salamanca, Universidad de Salamanca, 1997.

Anónimo, Las Etimologías romanceadas de San Isidoro, ed. de Joaquín González Cuenca, Salamanca, Universidad de Salamanca-CSIC-Institución Fray Bernardino de Sahagún-Diputación provincial de León, 1983.

Anónimo, Tesoro de la medicina (Tesoro de los remedios) (1431), Colombina 5117, ed. de María Teresa Herrera; María Estela González de Fauve, Madison, Hispanic Seminary of Medieval Studies, 1997.

Arce de Otálara, Juan de, Coloquios de Palatino y Pinciano, ed. de J. L. Ocasar Ariza, Madrid, Turner-Biblioteca Castro, 1995.

Armistead, Samuel G. and Joseph H. Silverman, "Algo más sobre 'Lo de tu abuela con el ximio' (La Celestina, I): Antonio de Torquemada y Lope de Vega.» Papeles de Son Armadans 205, (1973) pp. 11-18.

Armistead, Samuel G., James T. Monroe, \& Joseph H. Silverman , "Was Calixto's Grandmother a Nymphomaniac Mamlūk Princess? (A Footnote on "Lo de tu abuela con el ximio» [La Celestina, Aucto 1]), eHumanista, 14 (2010), pp.1-23.

Benítez Rodríguez, Enrique, "Atenea en el Corpus Paroemiographorum Graecorum», Paremia, 7 (1998), pp. 121-128.

Berceo, Gonzalo de, Vida de San Millán de la Cogolla, ed. de Brian Dutton, Madrid, Espasa-Calpe, 1992.

Bernaldo de Quirós, J. Antonio, «Comentarios a la hipótesis de García Valdecasas sobre la gestación de La Celestina», Espéculo, 30 (2005).

- "Sobre el papel de Rojas en la elaboración de La Celestina», Lemir, 12 (2008), pp. 325-339.

-, "La Celestina desde el punto de vista escénico. Consecuencias para la atribución de la autoría», Lemir, 13 (2009), pp. 97-108.

—, «El bachiller Fernando de Rojas acabó (y empeoró) la Comedia de Calisto y Melibea», Etiópicas, 5 (2009), pp. 162-184.

- , ed. Anónimo/Fernando de Rojas, 'Comedia de Calisto y Melibea'. Hacia la 'Celestina' anterior a Fernando de Rojas, Madrid, Manuscritos, 2010. 
Bershas, Henry, N., "Testigo es el cuchillo de tu abuelo (Celestina I)», Celestinesca, 2-1, (1978) pp. 7-11.

BlecuA, Alberto, "Minerva con el can o los falsos problemas filológicos», Revista de Literatura Medieval, 14 (2002), pp. 37-46.

BotTA, Patrizia, "La Celestina de Palacio en sus aspectos materiales», Boletín de la Real Academia Española, 73 (1993), pp. 25-50 y 347-366.

-, «El texto en movimiento (de la Celestina de Palacio a la Celestina posterior), en R. Beltrán y J. L. Canet (eds.), Cinco siglos de Celestina: aportaciones interpretativas, Valencia, Universidad de Valencia, (1997) pp. 135-159.

Burgos, Fray Vicente de (1494), Traducción de El Libro de Propietatibus Rerum de Bartolomé Anglicus, ed. de $M^{a}$ Teresa Herrera; Ma Nieves Sánchez, Salamanca, Universidad de Salamanca, 1999.

Camillo, Ottavio Di, "When and where was the firts act of La Celestina composed? A reconsideration» en Devid Paolini (Coord.) "De ninguna cosa es alegre posesión sin compañia». Estudios celestinescos y medievales en honor del profesor Joseph Thomas Snow, New York, Hispanic Seminary of medieval Studies, (2010), 1 vol., pp. 91-157.

Canet Vallés, José Luis (ed.), Comedia de Calisto y Melibea, Universidad de Valencia, PUV, col. Parnaseo, 2011.

Cantalapiedra Erostarbe, Fernando, Pour une analyse sémiotique de La Célestine de F. de Rojas, Thèse de III cycle. Université de Paris III, Sorbonne, Paris, janvier, 1979.

- Lectura semiótico-formal de "La Celestina», Kassel, Reichenberger, 1986.

-, "Apuntes didácticos sobre la estructura de La Celestina y el problema de su autoría", en Actas das I. Xornadas de didáctica da literatura, Santiago de Compostela, Univ. de Santiago de Compostela, 1987, pp.41-54.

—, "La escena de la huerta-huerto», en Criado de Val (dir.), Literatura Hispánica. Reyes Católicos y Descubrimiento, Barcelona, PPU, 1989, pp. 317-327.

- "Sentencias petrarquistas y adiciones a la TragiComedia de Calisto y Melibea», en P. Botta, F. Cantalapiedra, K. Reichenberger y J. T. Snow (eds.), Tras los pasos de 'La Celestina', Kassel, Edition Reichenberger, 2001, pp. 55-154.

-, "Risa, religiosidad y erotismo en La Celestina», en Ignacio Arellano y Jesús M. Usunáriz (eds.), El mundo social y cultural de 'La Celestina'. Actas del Congreso Internacional, Universidad de Navarra, junio, 2001, Madrid- Frankfurt, Iberoamerica-Vervuert, 2003, pp. 45-70.

-, "Alisa y Celestina, las comadres de las tenerías», en M $^{a}$ I. Sancho, L. Ruiz y F. Gutiérrez (eds.), Estudios sobre lengua, Literatura y Mujer, Universidad de Jaén, 2006, pp. 63-130.

-, "Fue tanto breve quanto muy sutil. Los paratextos de La Celestina», eHumanista, 19 (2011), pp. 20-79.

Castells, Ricardo, "El sueño de Celestina y la tradición celestinesca», Celestinesca, 14-1, (1990), pp. 17-39. 
Castro Guisasola, F., Observaciones sobre las fuentes literarias de 'La Celestina', Madrid, Revista de Filología Española, Anejo v, 1973.

ChIRIno, Alfonso (a 1429), Menor daño de la medicina, Escorial, b.rv.34, ed. de Enrica J. Ardemagni, Ruth M. Richards, Michael R. Salomon, Madison, Hispanic Seminary of Medieval Studies, 1987.

Conde, Juan Carlos, "El manuscrito II-1520 de la Biblioteca de Palacio: un nuevo testimonio del Diálogo de vita beata de Juan de Lucena", La Corónica, 21-2 (1993), pp. 34-57.

-, "El manuscrito II-1520 de la Biblioteca de Palacio y La Celestina: balance y estado de la cuestión", en R. Beltrán y J. L. Canet (eds.), Cinco siglos de Celestina: aportaciones interpretativas, Valencia, Universidad de Valencia, 1997, pp. 161-185.

Coplas de Mingo Revulgo glosadas por Fernando del Pulgar, Salamanca, Juan de Porras ¿1498?

Correas, Gonzalo, Vocabulario de refranes y frases proverbiales, ed. de Louis Combet, Burdeos, 1967.

Delicado, Francisco, La Lozana Andaluza, ed. de Claude Allaigre, Madrid, Cátedra, 1985.

Encina, Juan del, Égloga de Mingo, Gil y Pascuala, ed. de Miguel Ángel Pérez Priego, Madrid, Cátedra, 1991.

ESCUDERO, Juan M., "La expresión 'comedor / encomendador de huevos asados en La Celestina», Rivista di Filología e letterature Ispaniche, I (1998), pp. 197-201.

EspinosA, Francisco de, Refranero (1527-1547), edición de Eleanor S. O'kane, Madrid, Anejos del Boletín de la Real Academia Española, 1968. FaulHaber, Charles B., "Celestina de Palacio: Madrid, Biblioteca de Palacio, MS 1520», Celestinesca, 14-2 (1990), pp. 3-39.

-, "Celestina de Palacio: Rojas's Holograph Manuscript», Celestinesca, 15-1 (1991), pp. 3-52.

—, "MS 1520 de la Biblioteca de Palacio. De los "papeles del antiguo auctor' a la Comedia de Calisto y Melibea: Fernando de Rojas trabaja su fuente", en Literatura Medieval. Actas do IV Congresso da Associação Hispânica de Literatura Medieval (Lisboa, 1-5 Outubro 1991), Lisboa, edições Cosmos, vol. II, (1993), pp. 283-287.

Fernández-Rivera, Enrique, "Huevos asados': Nota marginal», Celestinesca, 17-1 (1993), pp. 57-60.

—, «El plebérico corazón, Erasístrato y la plétora», Celestinesca, 39 (2009), pp. 71-85.

FonTECHA, Diez privilegios para mujeres preñadas, ed. de $\mathrm{M}^{a}$ Purificación Zabía Lasala, Madrid, Arco Libros, 1999.

ForCADAS, Alberto M., "Otra solución a 'lo de tu abuela con el ximio' (Aucto 1) de 'La Celestina'», Romance Notes, 15-3 (1974), pp. 567-71. 
García de Castro, Diego, Seniloquium. Refranes que dizen los viejos, edición de Fernando Cantalapiedra y Juan Moreno, Valencia, PUV col. Parnaseo, 2006.

García de SAlazAr, Lope, Istoria de las bienandanzas e fortunas, ed. de Ana María Marín Sánchez, Madrid, CORDE, 2000, f. 97v.

Garci-Gómez, Miguel, «'Huevos asados', afrodisíaco para el marido de Celestina", Celestinesca, 5 (1981), pp. 23-34. También en red: <http,// mgarci.aas.duke.edu/celestina/CELESTINA/ENSA/HUEVOS.HTM>.

—, "El sueño de Calisto», Celestinesca, 9-1, (1985), pp.11-22.

—, "El ximio [mono] de la abuela y el cuchillo del abuelo de Calisto: identificación». <http://mgarci.aas.duke.edu/celestina $>$.

GarCi-Gómez, Miguel, «Sobre el plebérico coraçón de Calisto y la razón de Pleberio", en <http://mgarci.aas.duke.edu/celestina/CELESTINA/ ENSA/PLEBERIO.HTM>.

García Valdecasas, José Guillermo, La adulteración de 'La Celestina', Madrid, Castalia, 2000.

García, Michel, "Consideraciones sobre Celestina de Palacio", Celestinesca, 18-1, (1994), pp. 3-16.

-, "Apostillas a 'Consideraciones sobre Celestina de Palacio", Celestinesca, 18-2, (1994), pp.145-149.

General Estoria, Segunda parte, ed. de Pedro Sánchez-Prieto Borja, Alcalá de Henares, Universidad de Alcalá, 2003.

Gillet, Joseph E., "Comedor de huevos (?). Celestina, auto I», Hispanic Review, 24 (1956), pp.144-147.

Goldman, Peter B., "A new interpretation of "comedor de huevos asados (La Celestina, aucto I)", Romanische Forschungen, LXXVII (1965), pp. 363-367.

Gómez Canseco, Luis, "El cuchillo de tu abuelo. En torno a la edición de un lugar oscuro en el acto I de LC», Celestinesca, 39 (2015), pp. 27-38.

Gómez Manrioue, Cancionero, ed. de Francisco Vidal González, Madrid, Cátedra, 2003.

Green, Otis H., "Minerva con el can", Nueva Revista de Filología Hispánica, VII (1953), pp. 470-74.

-, "Lo de tu abuela con el ximio' (Celestina, auto I)", Hispanic Review, XXIV-1 (1956), pp. 1-12.

Grimal, Pierre, Diccionario de mitología griega y romana, Barcelona, Paidós, 1991.

Herrero Llorente, V. J., Diccionario de frases y expresiones latinas, Madrid, Gredos, 1992.

Horozco, Sebastián de, El libro de los Proverbios glosados, ed. de Jack Weiner, Kassel, Edition Reichenberger, 1994.

INFANTES, Víctor, "Los libros 'traýdos y viejos y algunos rotos' que tuvo el bachiller Fernando de Rojas, nombrado autor de la obra llamada Celestina», Bulletin Hispanique, 100 (1998), pp. 1-51. 
-, La trama impresa de 'Celestina'. Ediciones, libros y autográfos de Fernando de Rojas, Madrid, Visor Libros, 2010.

Juan del Encina, Égloga de Mingo, Gil y Pascuala, ed. de Miguel Ángel Pérez Priego, Madrid, Cátedra, 1991.

Kathleen, Kish, y Ursula Ritzenhoff, "On translating 'huevos asados': clues from Christof Wirsung», Celestinesca, 2 (1981), pp. 19-31.

Krause, Anna, "Deciphering the epistle-preface to the Comedia de Calisto y Melibea», Romanic Review, XLIV (1953), pp. 89-101.

Leutsch y Schneidewin (1839 y 1851), Corpus Paroemiographorum graecorum, Gotinga. Reeditado por George Olms en 1965.

Lobera Serrano, Francisco J., "El Manuscrito 1.520 de Palacio y la tradición impresa de La Celestina», Boletín de la Real Academia Española, 73 (1993), pp. 51-67.

Lobera y Alii, Fernando de Rojas (Y antiguo autor), La Celestina. Tragicomedia de Calisto y Melibea, Barcelona, Crítica, 2000.

López de Ayala, Pero, Libro de la caça de las aves, ed. de José Manuel Fradejas Rueda, Madison, Hispanic Seminary of Medieval Studies, 1995.

Lozano-Renieblas, Isabel, «Minerva con el can», Celestinesca, 15-1 (1991), pp.75-78.

LunA, Juan de, Diálogos familiares en lengua española, París, 1619 y Bruselas: chez Hubert Antoine,1625. Lo edita asimismo José María Sbarbi, Madrid, Impr. Gómez Fuentenebro, 1874.

Marciales, Miguel, Fernando de Rojas, Celestina. Tragicomedia de Calisto y Melibea, al cuidado de Brian Dutton y Joseph T. Snow, Urbana and Chicago, University of Illinois Press, 1985, 2 vols.

Maroués de Santillana, Comedieta de Ponza, sonetos, serranillas y otras obras, ed. de. R. Rohland de Langbehn; estudio preliminar de V. Beltrán, Barcelona, Crítica, 1997.

Martínez de Toledo, Alfonso, Arcipreste de Talavera o Corbacho, ed. de Michael Gerli, Madrid, Cátedra, 1988.

McGrady, Donal, "Two Stdies on the Text of the Celestina» y en particular «Eras, Crato, Erasístrato, Seleuco and 'el plebérico coraçon': An Explication", Romance Philology, 48 (1994), pp. 1-21.

Menéndez y Pelayo, Marcelino, Orígenes de la novela, Madrid, 1962.

Michael, Ian, «La Celestina de Palacio: el redescubrimiento del MS. II-1520 (sign. Ant. 2. A.4) y su procedencia segoviana», Revista de Literatura Medieval, III (1991), pp. 149-171.

Morros, Bienvenido, «La difusión de un diagnóstico de amor desde la antigüedad a la época moderna", BRAE, LXXIX (1999), pp. 93-150.

MuÑoz Llamosas, Virginia, «Insultos e invectiva entre Demóstenes y Esquines», Minerva, 21 (2008), pp. 33-49.

Núñez, H., Refranes o proverbios en romance, ed. crítica de L. Combet, J. Sevilla, G. Conde, y J. Guia, Madrid, Guillermo Blázquez editor, 2001, dos tomos. 
Pardo Pastor, J. , "Alonso de Proaza, 'homo litterarum, corrector et excelsus editor'", Covenit Selecta, 3 (2000): <http://www.hottopos.com/convenit3/jordipar.htm\#_ftnref10>.

Penney, Clara Louisa, The book Called "Celestina" in the Library of the Hispanic Society of America, New York, The Hispanic Society of America, 1954.

Plutarco, Vidas paralelas, trad. de Alfonso de Palencia, Sevilla, 1491; y la edición de Zaragoza de 1495 (Ugo de Urries).

_, Vidas paralelas, edición de José Alsina, Barcelona, Planeta, 1990.

Quevedo, Francisco de, Poesía varia, ed. de James O. Crosby, Madrid, Cátedra, 1981.

RichthOFen, Erich von, "Lo de la 'abuela con el ximio': otra expresión humanística y caballeresca (de LC)?», Cuadernos para Investigación de la Lit. Hispánica, 5 (1983), pp. 133-34.

Riquer, Martín de, "Fernando de Rojas y el primer acto de 'La Celestina'», Revista de Filología Española, XLI-1/4 (1957), pp. 371-395.

Rodríguez de Montavo, Garci, Amadís de Gaula, edición de Juan Manuel Cacho Blecua, Madrid, Cátedra, 1988.

-, Las sergas de Esplandián, Alcalá de Henares, Herederos de Juan Gracián, 1588. BNM, signatura R/ 13138 (1).

RojAs, Fernando de (y 'antiguo autor'), La Celestina. Tragicomedia de Calisto y Melibea, edición y estudio de F. J. Lobera, G. Serés, P. Díaz-Mas, C. Mota, I. Ruiz Arzallus, y F. Rico. Barcelona, Crítica, 2000.

Ruiz Arzállus, Íñigo, "El mundo intelectual del 'antiguo autor': las Auctoritates Aristotelis en la Celestina primitiva», B.R.A.E., LXXVI, Cuaderno CCLXIX, (1996), pp. 265-284.

RuIz, Juan, Libro de buen amor, ed. de Alberto Blecua, Madrid, Cátedra, 1992.

Russell Thompson, B., "Misogyny and Misprint in La Celestina, Acto I", Celestinesca, 1-2 (1977), pp. 21-28.

Sánchez Sánchez-Serrano, Antonio, Mensaje de 'La Celestina'. Análisis de un proceso de comunicación diferida, Madrid, Universidad Complutense de Madrid, Colección Tesis doctorales, 1988.

Sánchez Sánchez-Serrano, Antonio y Ma Remedios Prieto de la Iglesia, Fernando de Rojas y 'La Celestina', Barcelona, Teide, 1991.

-, "Sobre la composición de La Celestina y su anónimo 'auctor'», Celestinesca, 33 (2009), pp. 143-171.

Serés, Guillermo, «Primeros textos y fortuna editorial (siglos XVI y XVII), en Fernando de Rojas (y 'antiguo autor'), La Celestina. Tragicomedia de Calisto y Melibea.

Silva, Feliciano de, Segunda Celestina, edición de Consolación Baranda. Madrid, Cátedra, 1988. 
Simone, Carla, La prima traduzione italiana della "Celestina" de i suori rapporti con la edizioni primitive in lingua spagnola, tesis Univ. De Roma, dir. E. Scoles, 1991.

SNow, Joseph T., "La problemática autoría de Celestina», Incipit, XXV-XXVI (2005-2006), pp. 537-561.

Torregrosa DíAz, José Antonio, "Tragicomedia de Calisto y Melibea». Anotaciones Críticas y Textuales y Versión Modernizada, Tesis doctoral, Universidad de Murcia, 2015.

VALLÉs, Pedro, Libro de refranes, 1549.

VASVARI FAINBERG, Louise $\bigcirc$., "¡O, qué comedor de huevos assados era su marido!: Farther Glosses on the vocaburlario of Celestina, IV», en José Manuel Hidalgo (ed.) 'La pluma es la lengua del alma'. Ensayos en honor de E. Michael Gerli, Neward, Delaware, Juan de la Cuesta, 2011, pp. 367-386.

VIGIER, Françoise, "Quelques reflexions sur le lignage, la parenté et la famille dans la 'celestinesque'", en Autour des parentés en Espagne aux xvi et xviì siècles. Histoire, mythe et littérature, ed. de A. Redondo, París, La Sorbonne, 1987, pp. 157-174.

Villena, Enrique de, Traducción y glosas de 'La Eneida'. Libros I-III, ed. de Pedro M. Cátedra, Madrid, Turner Libros, 1994. 


\section{Cantalapiedra Erostarbe, Fernando, «Notas sobre El Manuscrito de Palacio II-1520, adiciones marginales y controversias filológicas», Celestinesca 40 (2016), pp. 9-52.}

\section{RESUMEN}

Tras señalar la evolución en los últimos años de la percepción crítica sobre la autoría de $L C$, el presente artículo se fija en los dos subconjuntos que configuran el Manuscrito de Palacio, $M p$ - $a$ y $M p$ - $b$, centrándose en el primero de ellos y en algunas de las modificaciones textuales del segundo copista. Establece que derivan de modelos distintos, y que las glosas marginales son adiciones del segundo amanuense que terminan incorporándose al texto impreso, y que este mismo proceso se aplicó a los doce actos de la comedia terenciana. Propone asimismo algunas sugerencias como solución a los problemas textuales planteados por Minerva, el can, el simio, el cuchillo y los huevos cocidos.

PALABRAS ClAVE: Autoría, manuscrito, grillos, vela, glosas, Erasístrato, Antíoco, plebérico, Minerva, can, simio, cuchillo, huevos, comadres

\section{RÉSUMÉ}

Après avoir signalé l'évolution dans ces dernières années de la pensée de la critique sur la paternité de LC, cet article fixe son attention sur les deux sous-ensembles qui configurent le Manuscrito de Palacio, le $M p$-a et le $M p$ - $b$, tout particulièrement sur le premier et sur quelques modifications dues au deuxième copiste. Il établit que ceux-ci dérivent de modèles différents, que les gloses marginales sont des additions textuelles introduites par le deuxième copiste qui finissent par se fixer définitivemente dans le texte imprimé; ce même procédé a été appliqué aux douze actes de la comédie à la manière de Térence. L'article propose aussi quelques solutions pour résoudre les problèmes textuels de Minerve, du chien, du singe, du couteau et des oeufs cuits.

KEY WORDS: Paternité, manuscrit, grillons, bougie, gloses, Erasistrate, Antioche, plébérique, Minerve, chien, singe, couteau, oeufs, commères.

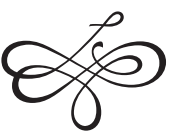

